\title{
A meta-analysis of public microarray data identifies biological regulatory networks in Parkinson's disease
}

\author{
Lining $\mathrm{Su}^{1}$, Chunjie Wang ${ }^{2}$, Chenqing Zheng ${ }^{3}$, Huiping $\mathrm{Wei}^{\mathrm{i}^{*}}$ and Xiaoqing Song ${ }^{1}$
}

\begin{abstract}
Background: Parkinson's disease (PD) is a long-term degenerative disease that is caused by environmental and genetic factors. The networks of genes and their regulators that control the progression and development of PD require further elucidation.

Methods: We examine common differentially expressed genes (DEGs) from several PD blood and substantia nigra (SN) microarray datasets by meta-analysis. Further we screen the PD-specific genes from common DEGs using GCBI. Next, we used a series of bioinformatics software to analyze the miRNAs, IncRNAs and SNPs associated with the common PD-specific genes, and then identify the mTF-miRNA-gene-gTF network.

Result: Our results identified 36 common DEGs in PD blood studies and 17 common DEGs in PD SN studies, and five of the genes were previously known to be associated with PD. Further study of the regulatory miRNAs associated with the common PD-specific genes revealed 14 PD-specific miRNAs in our study. Analysis of the mTF-miRNA-gene-gTF network about PD-specific genes revealed two feed-forward loops: one involving the SPRK2 gene, hsa-miR-19a-3p and SPI1, and the second involving the SPRK2 gene, hsa-miR-17-3p and SPI. The long non-coding RNA (IncRNA)-mediated regulatory network identified IncRNAs associated with PD-specific genes and PD-specific miRNAs. Moreover, single nucleotide polymorphism (SNP) analysis of the PD-specific genes identified two significant SNPs, and SNP analysis of the neurodegenerative disease-specific genes identified seven significant SNPs. Most of these SNPs are present in the 3'-untranslated region of genes and are controlled by several miRNAs.

Conclusion: Our study identified a total of 53 common DEGs in PD patients compared with healthy controls in blood and brain datasets and five of these genes were previously linked with PD. Regulatory network analysis identified PDspecific miRNAs, associated long non-coding RNA and feed-forward loops, which contribute to our understanding of the mechanisms underlying PD. The SNPs identified in our study can determine whether a genetic variant is associated with PD. Overall, these findings will help guide our study of the complex molecular mechanism of PD.
\end{abstract}

Keywords: Parkinson's disease, Long non-coding RNA, microRNA, SNPs, Network

\section{Background}

Parkinson's disease (PD) is one of the most common neurodegenerative diseases. The main symptoms of PD include shaking, bradypragia and postural instability [1]. PD is characterized by the loss of dopaminergic neurons in the substantia nigra $(\mathrm{SN})$ in brain,

\footnotetext{
* Correspondence: whp123456@sina.com

'Department of Biology of Basic Medical Science College, Hebei North

University, Zhangjiakou 075000, Hebei, China

Full list of author information is available at the end of the article
}

which involves the increase of microglia, and the presence of Lewy bodies [2].

Many studies have indicated that PD may be the result of a combination of genetic and environmental factors, such as exposure to pesticides, metals, solvents, and other toxicants [3]. Approximately $15 \%$ of individuals affected by PD have a family member with the disease [4] and $5-10 \%$ of people with PD are affected by a single specific gene mutation [5]. Previous studies have indicated that mutations in several specific genes cause PD, including genes encoding alpha-synuclein (SNCA), 
leucine-rich repeat kinase 2 (LRRK2), glucocerebrosidase (GBA), parkin (PRKN), PTEN-induced putative kinase 1 (PINK1), parkinson disease protein 7 (PARK7), vacuolar protein sorting-associated protein 35 (VPS35), eukaryotic translation initiation factor 4 gamma 1 (EIF4G1), dnaJ heat shock protein family (Hsp40) member C13 (DNAJC13) and coiled-coil-helix-coiled-coilhelix domain containing 2 (CHCHD2) [6]. The SNCA gene plays an important role in PD, because the encoded protein is the main component of Lewy bodies, which accumulate in the brains of people with PD [7]. Mutations in the SNCA gene have been found in different groups with sporadic (non-familial) PD and familial PD [5]. Mutations in the LRRK2 gene, which encodes a protein called dardarin, are associated with many familial and sporadic PD patients [8]. A recent study showed that carriers of the G2385R variant in the LRRK2 gene showed more of a tendency towards fatigue than noncarriers in PD patients [9]. A mutation in GBA is proposed to be the greatest genetic risk of PD through its effects in increasing the levels of SNCA [10]. The GBA variant E326K (rs2230288) was significantly more frequent in PD patients compared with controls, indicating that this variant is a susceptibility allele for PD [10]. Mutations in PINK1, PRKN, and PARK7 genes may cause mitochondrial dysfunction, which are observed in PD [11]. Some evidence has shown that low concentrations of urate in the blood serum increase the risk of PD [12].

These above studies improve our understanding of the molecular mechanism in PD. However, discordance among those studie make the combination of results from many similar studies difficult. However, metaanalysis uses statistical techniques to get combining information from multiple existing studies can increase the power and generalizability of results in PD [13]. A limited number of meta studies has been conducted on gene expression profiles to identify novel biomarkers for PD. However, different microarray data combination, different sizes of each individual study combination, and different statistical methods are among the factors contributed to the different results. For instance, Elisa Mariani et al. [14] used TRAM Software to conduct a metaanalysis of PD transcriptome data. Chang D et al. [15] carried out a meta-analysis with a recent study of over 13,000 PD cases and 95,000 controls with estimating the $\mathrm{h} 2$ value for $\mathrm{PD}$, and then identified 17 new PD risk loci. Wang $Q$ et al. [16] performed a meta-analysis with 9 microarray datasets of PD studies in every brain region using the RankProd method [17].

Our meta-analysis was conducted on PD patients and healthy controls microarray datasets obtained from the $\mathrm{SN}$ brain region and blood using Vote counting generic ways. In this study, five independent SN microarrays (GSE7621, GSE8397-GPL96, GSE8397-GPL97, GSE20163, and GSE20141) from PD patients and healthy controls were integrated and analyzed to screen common differentially expressed genes (DEGs). We also performed a metaanalysis of three independent blood microarrays (GSE99039, GSE6613, and GSE72267) from PD patients and healthy controls to screen common DEGs.

MicroRNAs (miRNAs) are small non-coding RNA molecules ( $22 \mathrm{nt}$ long) that are found in plants, animals and some viruses and have been proven to play crucial roles in gene expression. Long non-coding RNAs (lncRNAs), longer than $200 \mathrm{nt}$, can control gene expression by interacting with the miRNA pathways [18]. LncRNAs binds to miRNAs through miRNA response elements or binding sites to regulate miRNA target gene expression [18]. Several studies have revealed that non-coding RNAs, such as miRNAs and lncRNAs, have been implicated in PD pathogenesis [13].

Finally, we examined the regulatory network involving genes, miRNAs, transcription factors (TFs) and lncRNA in PD progression to better understand the molecular mechanisms involved in this disease. In our study, we use some same bioinformatics software and similar methodological workflow as the recently published paper [13].

\section{Methods}

Our overarching goal was to identify candidate biomarkers of PD (the focus of this study) using the follow workflow (Fig. 1).

\section{Data collection}

We used "Parkinson's disease" as keywords to search for genome-wide expression studies in NCBI-GEO (http:// www.ncbi.nlm.nih.gov/geo/) and EMBL-EBI ArrayExpress databases (https://www.ebi.ac.uk/arrayexpress/). Only original experimental studies that screened for different genes between PD and healthy humans were the first choice for inclusion. Additional inclusion criteria included the following: (1) the study type was expression profiling by array; (2) Studies which comprised of cell intensity file (CEL) raw files were available; and (3) studies about blood or brain $\mathrm{SN}$ in PD were used in the analysis. With the inclusion criteria, three datasets from blood and five datasets from $\mathrm{SN}$ in $\mathrm{PD}$ were screened. We then performed meta-analysis of three datasets from blood studies (GSE99039, GSE6613, and GSE72267) and five datasets from SN studies (GSE7621, GSE8397GPL96, GSE8397-GPL97, GSE20163, and GSE20141). Details of the microarray datasets are provided in Table 1.

Searches were executed up to August 2017. 


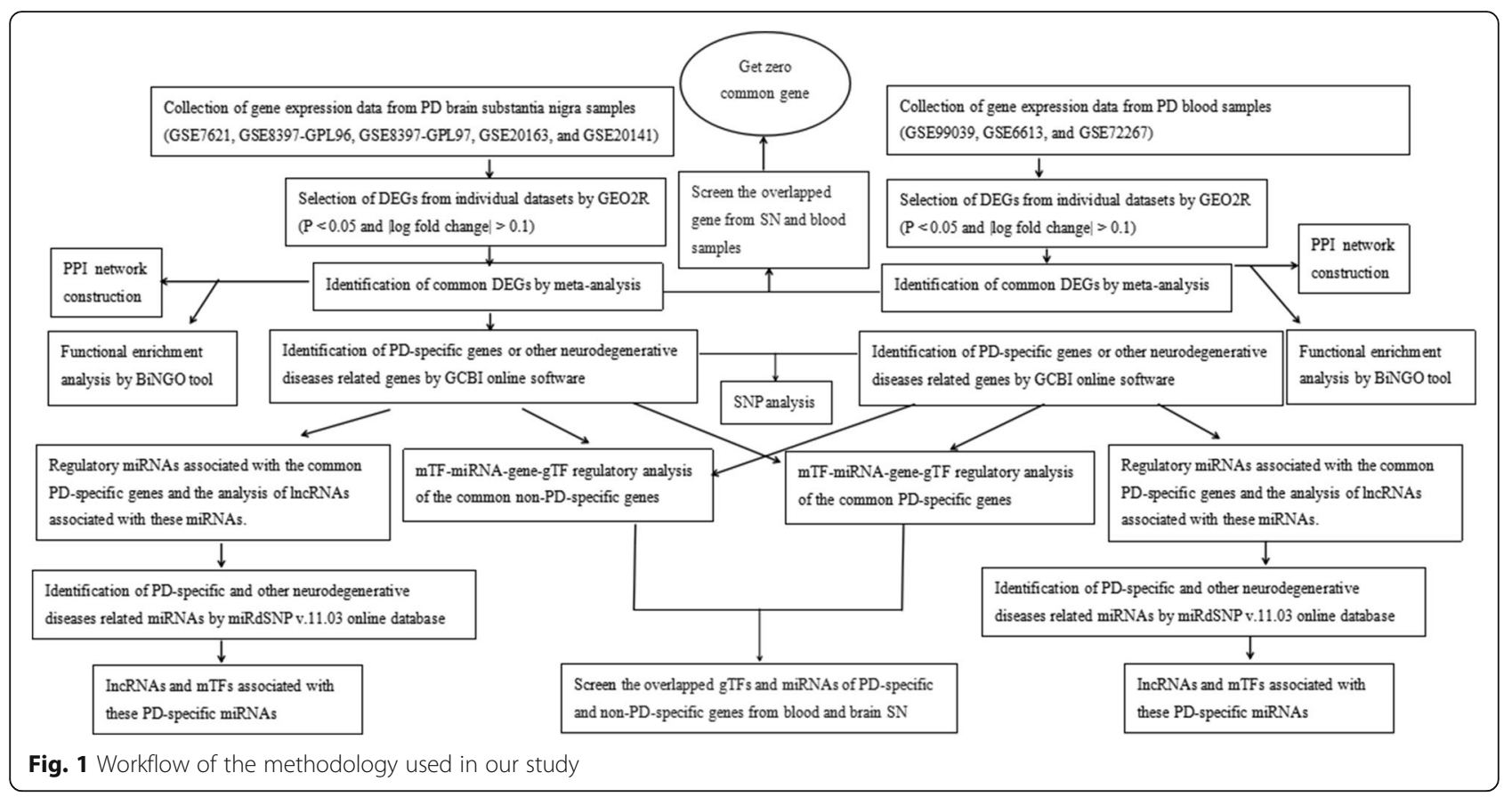

\section{Inclusion criteria for DEGs}

GEO2R is an interactive web tool that is based on GEOquery and limma $R$ packages from the Bioconductor project that is used to identify DEGs by comparing different groups of GEO Series samples [19]. In this study, each individual dataset was processed using the GEO2R online software to compare healthy control samples and PD patient samples to screen DEGs. The $t$ test and Benjamini and Hochberg method were used to calculate the $P$ values and FDR, respectively [20]. Genes that were differentially expressed between PD and healthy controls were screened with the threshold value of $P<0.05$ and $\mid \log$ fold change $\mid>0.1$. The probes with no gene annotation or matched multiple gene symbols were removed, and when multiple probes matched to the same gene symbol, we selected the probe with the highest $\mid \log$ fold change| value.

\section{Meta-analysis of DEGs of gene expression microarray datasets}

Here, Meta-analysis was performed on the three datasets from blood studies and five datasets from brain SN independently using Vote counting generic ways of combining information [21]. The results were visualized using a Venn diagram that were plotted using the OmicShare tools, a free online platform for data analysis (http:// www.omicshare.com/tools).

Next, we mainly used GCBI online software to identify common DEGs associated with PD as PD-specific genes, and to identify other neurodegenerative diseases as other neurodegenerative diseases related genes.

\section{Functional enrichment analysis}

BiNGO is a tool to determine the Gene Ontology (GO) categories that are statistically overrepresented in a set of genes or a subgraph of a biological network [22]. BiNGO was used to analyze GO enrichment of DEGs in blood tissues and in brain SN of PD. GO enrichment with $p<0.05$ and false discovery rate $(\mathrm{FDR})<0.05$ was regarded as statistically significant.

\section{Protein-protein interaction (PPI) network construction for common DEGs}

The selected common genes from SN tissue and blood were subjected to STRING v.10.5 database [23] analysis to construct PPI networks. The threshold value was a score of 0.4. PPI networks were visualized by Cytoscape software v. 3.4.0 [24] and analyzed using the Network Analyzer tool based on degree. The degree indicates the number of interactions of a particular protein. The size of the node is proportional to the degree in the interaction network. The more the nodes connected to the node, the larger the node will be. Large nodes indicate bigger degrees. In this network, we selected some genes that are with a high node degree. At last, the top three nodes with degree values above the average network degree value were identified.

\section{Biological regulatory interaction and networks for common PD-specific genes from our study}

Experimentally validated miRNA and common PDspecific gene interactions were analyzed using DIANA-Tarbase [25]. We also examined lncRNA and 
Table 1 Datasets used in the meta-analysis

\begin{tabular}{|c|c|c|c|c|}
\hline Tissue & GEO Accession & Sample Size(control/PD) & Platform & PMID \\
\hline \multirow[t]{3}{*}{ Blood } & GSE99039 & $P D=205 ; H C=233$ & GPL570: Affymetrix Human Genome U133 Plus 2.0 Array & $28,916,538[90]$ \\
\hline & GSE6613 & $P D=50 ; H C=22$ & GPL96: Affymetrix Human Genome U133A Array & $17,215,369[91]$ \\
\hline & GSE72267 & $\mathrm{PD}=40 ; \mathrm{HC}=19$ & GPL571: Affymetrix Human Genome U133A 2.0 Array & $26,510,930[92]$ \\
\hline \multirow[t]{5}{*}{ SN } & GSE7621 & $P D=16 ; H C=9$ & GPL570: Affymetrix Human Genome U133 Plus 2.0 Array & $17,571,925[93]$ \\
\hline & GSE8397-GPL96 & $P D=24 ; H C=15$ & GPL96: Affymetrix Human Genome U133A Array; & $16,344,956[94]$ \\
\hline & GSE8397-GPL97 & $P D=24 ; H C=15$ & GPL97: Affymetrix Human Genome U133B Array & \\
\hline & GSE20141 & $P D=10 ; H C=8$ & GPL570: Affymetrix Human Genome U133 Plus 2.0 Array & $20,926,834[95]$ \\
\hline & GSE20163 & $\mathrm{PD}=8 ; \mathrm{HC}=9$ & GPL96: Affymetrix Human Genome U133A Array & $20,926,834[95]$ \\
\hline
\end{tabular}

$P D$ Parkinson's disease, $H C$ healthy control

miRNA interactions using DIANA-LncBase Experimental v.2 [26]. This database contains more than 70,000 low and high-throughput, (in)direct miRNA: lncRNA experimentally supported interactions, derived from manually curated publications and the analysis of 153 AGO CLIP-Seq libraries [26]. Experimentally validated (prediction score $\geq 0.90$ ) lncRNAs were selected in our study.

To study molecular regulator interactions, we built a regulatory network comprising common PD-specific genes, TFs associated with the genes, miRNAs associated with the genes and TFs associated with the miRNAs. Information on TFs binding site that were associated with the genes was obtained from TRANSFAC [27] based on the Match $^{\mathrm{Tm}}$ algorithm. The TRANSFAC database contains data from a wide variety of eukaryotic organisms, ranging from human to yeast and comprising data on transcription factors, their target genes and regulatory binding sites [27]. In our study, the search algorithm uses two score values, the matrix similarity score (MSS) and the core similarity score (CSS), to estimate the result. Finally, the inclusion criteria was score $=1$ for the MSS and CSS. The gene-miRNA interaction information was analyzed using DIANA-Tarbase [25]. Regulatory information on the TFs associated with these miRNAs was obtained from the TransmiR database [28]. We then generated the network using Cytoscape software v. 3.4.0 [24].

PD-specific and other neurodegenerative diseases related miRNAs identified from miRNAs associated with the PD-specific genes were filtered from miRdSNP v.11. 03 online database [29].

The analysis of IncRNAs and mTFs associated with these PD-specific miRNAs related to the PD-specific genes

To identify possible lncRNA-mediated regulation of the PD-specific miRNAs associated with common PDspecific genes of our study, we collected regulatory information in the lncbase module of DIANA-LncBase v.2 [26]. The experimentally validated lncRNAs (score $\geq 0.90$ ) were selected in our study. Regulatory information on the TFs that were associated with these miRNAs was obtained from the TransmiR v.1.2 database [26]. We then got a regulatory pattern involving the TFs, lncRNAs and common PD-specific genes associated with the PD-specific miRNAs.

Regulatory analysis of the common non-PD-specific genes To study the molecular regulator interactions with the common non-PD-specific genes, we perform regulatory analysis including TFs associated with the genes, miRNAs associated with the genes and TFs associated with the miRNAs. Information on the TFs that were associated with the genes was obtained from TRANSFAC [27] and the inclusion criteria was score $=1$ for the MSS and CSS. The gene-miRNA interaction information was analyzed using DIANA-Tarbase v.7.0 [25], miRWalk database v.3.0 [20] and TargetScan human v.7.1 [30]. Regulatory information on the TFs that were associated with these miRNAs was obtained from the TransmiR v. 1.2 database [28].

PD-specific miRNAs identified from miRNAs associated with the common non-PD-specific genes were filtered from miRdSNP v.11.03 online database [29].

\section{SNP analysis of the common PD-specific and other neurodegenerative disease-specific genes}

To identify PD-associated SNPs, the common genes in our study were subjected to SNP analysis. SNPs corresponding to these genes were identified from the MirSNP online database (http://bioinfo.bjmu.edu.cn/ mirsnp/search/) [31]. We obtained a large number of SNPs related to the genes. To identify the PD-specific or neurodegenerative disease-specific SNPs from this large number of SNPs, we screened the SNPs in miRdSNP v. 11.03 [29] and LincSNP v.2.0 [32]. Chromosome locus and allele gene information corresponding to each of the SNPs were searched using the dbSNP database(https:// www.ncbi.nlm.nih.gov/snp/?term=). 


\section{Results}

\section{Meta-analysis of DEGs and PD-specific or other} neurodegenerative diseases related DEGs identification

To identify DEGs between PD and healthy controls, we used three datasets from blood and five datasets from the brain $\mathrm{SN}$ region to perform meta-analyses and detected common genes across these datasets. The analyses revealed that 28 downregulated genes and 8 upregulated genes were differentially expressed in the three blood studies (Fig. 2a, b and Table 2). Out of the total 36 DEGs in the blood studies, 19 were previously known to be associated with several other neurodegenerative diseases, such as Alzheimer's disease and four common genes (HSPA6, MAP2K6, SRPK2 and NOL7) were also previously associated with PD (named PD-specific genes)(identified using GCBI online software). We also identified 11 downregulated and 6 upregulated genes as differentially expressed in the five brain SN studies (Fig. 2c, d and Table 3). Among the 17 total DEGs in the brain SN studies, nine genes have been previously associated with neurodegenerative diseases, and one gene
(SNCA) was identified as PD-specific genes(identified using GCBI online software). Overall, the number of downregulated genes was greater than the number of upregulated genes.

\section{GO functional enrichment analysis of all common DEGs}

The common DEGs from blood and brain SN were then subjected to enrichment analysis in BiNGO. The common DEGs in blood were enriched in biological processes (BP) of protein phosphorylation, DNA damageinduced protein phosphorylation, phosphorylation, response to gamma radiation and $\mathrm{B}$ cell lineage commitment, among other processes (Additional file 1: Table S1 and Fig. 3). DEGs from brain SN were enriched in BP including cellular nitrogen compound biosynthetic process, negative regulation of G-protein coupled receptor protein signaling pathway, pigment biosynthetic process, regulation of acyl-CoA biosynthetic process, negative regulation of neurotransmitter uptake and negative regulation of catecholamine uptake involved in synaptic transmission (Additional file 1: Table S2 and
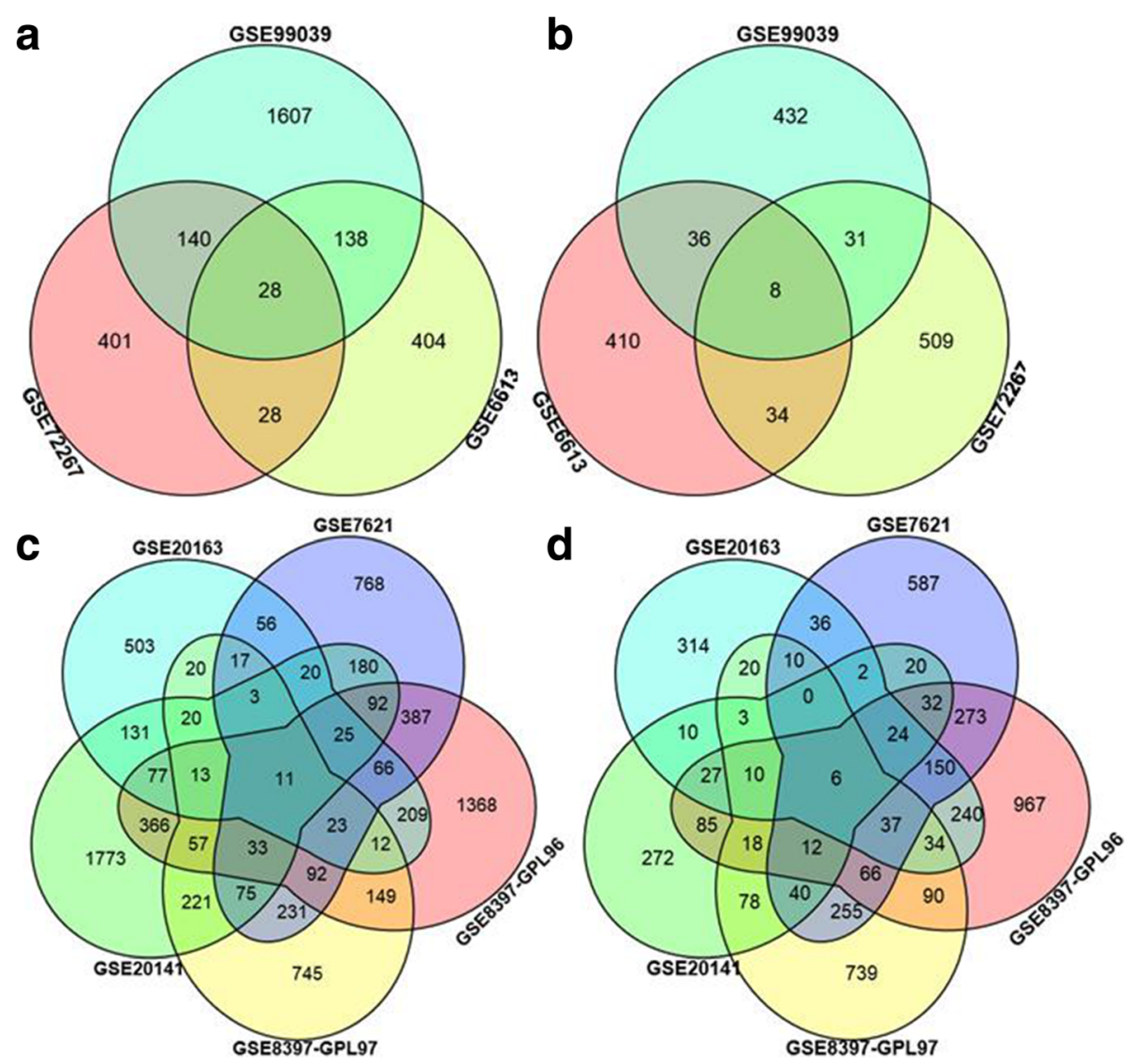

Fig. 2 The number of common genes obtained from blood and substantia nigra (SN) expression profiling datasets visualized by a Venn diagram. a The number of downregulated genes in expression profiling datasets from blood; $\mathbf{b}$ The number of upregulated genes in expression profiling datasets from blood; c The number of downregulated genes in expression profiling datasets from SN; and $\mathbf{d}$ The number of upregulated genes in expression profiling datasets from SN 
Table 2 Common differentially expressed genes identified from blood in PD patients and healthy controls and that PD-specific and other neurodegenerative diseases related genes identification

\begin{tabular}{|c|c|c|c|}
\hline Expression & Gene symbol & Gene name & $\begin{array}{l}\text { Corresponding neurodegenerative } \\
\text { disease other than PD }\end{array}$ \\
\hline \multirow[t]{28}{*}{ Down-regulated } & $\mathrm{ABCA} 1^{\mathrm{a}}$ & ATP binding cassette subfamily A member 1 & Alzheimer's disease \\
\hline & ABHD5 & abhydrolase domain containing 5 & \\
\hline & ADGRG3 & adhesion G protein-coupled receptor G3 & \\
\hline & AKAP13 $3^{a}$ & A-kinase anchoring protein 13 & Alzheimer's disease \\
\hline & APMAPa & adipocyte plasma membrane associated protein & $\begin{array}{l}\text { Multiple sclerosis; Alzheimer's } \\
\text { disease }\end{array}$ \\
\hline & ARG1 & arginase 1 & \\
\hline & $B A Z 1 A^{a}$ & bromodomain adjacent to zinc finger domain $1 \mathrm{~A}$ & Huntington disease \\
\hline & $B M X^{a}$ & BMX non-receptor tyrosine kinase & Alzheimer's disease \\
\hline & $C D K L 5^{a}$ & cyclin dependent kinase like 5 & \\
\hline & CEBPD $^{a}$ & CCAAT/enhancer binding protein delta & Alzheimer's disease \\
\hline & CSF2RA ${ }^{a}$ & colony stimulating factor 2 receptor alpha subunit & Alzheimer's disease \\
\hline & $\mathrm{CTBP}^{\mathrm{a}}$ & C-terminal binding protein 2 & Alzheimer's disease \\
\hline & FAM120A ${ }^{a}$ & family with sequence similarity $120 \mathrm{~A}$ & Multiple sclerosis \\
\hline & $H L A-C^{a}$ & major histocompatibility complex, class I, C & Multiple sclerosis \\
\hline & HSPA6 ${ }^{\mathrm{b}}$ & heat shock protein family A (Hsp70) member 6 & \\
\hline & IRS2 & insulin receptor substrate 2 & \\
\hline & LILRB1 & leukocyte immunoglobulin like receptor B1 & \\
\hline & LRRFIP1 ${ }^{a}$ & LRR binding FLII interacting protein 1 & $\begin{array}{l}\text { Multiple sclerosis; Huntington } \\
\text { disease }\end{array}$ \\
\hline & MAP2K6 ${ }^{\mathrm{b}}$ & mitogen-activated protein kinase kinase 6 & \\
\hline & MAP2K7 & mitogen-activated protein kinase kinase 7 & \\
\hline & MGAM & maltase-glucoamylase & \\
\hline & NCAM1 & neural cell adhesion molecule 1 & \\
\hline & NCOA3 & nuclear receptor coactivator 3 & \\
\hline & $\mathrm{PML}^{\mathrm{a}}$ & promyelocytic leukemia & Polyglutamine diseases \\
\hline & SRPK2 $2^{b}$ & SRSF protein kinase 2 & \\
\hline & SUPT2OH & SPT20 homolog, SAGA complex component & $\begin{array}{l}\text { Cerebellar Purkinje cell } \\
\text { degeneration }\end{array}$ \\
\hline & $\mathrm{THOC}^{\mathrm{a}}$ & THO complex 2 & Multiple sclerosis \\
\hline & $\mathrm{TM} \times 4^{\mathrm{a}}$ & thioredoxin related transmembrane protein 4 & Motor neuron disease \\
\hline \multirow[t]{8}{*}{ Up-regulated } & ATM & ATM serine/threonine kinase & \\
\hline & $\mathrm{BCL} 2^{\mathrm{a}}$ & $\mathrm{BCL2}$, apoptosis regulator & Alzheimer's disease \\
\hline & FAM102A & family with sequence similarity 102 member A & Neurodegenerative disease \\
\hline & LRRN3 & leucine rich repeat neuronal 3 & \\
\hline & $\mathrm{NOL7}^{\mathrm{b}}$ & nucleolar protein 7 & \\
\hline & TCF3 & transcription factor 3 & \\
\hline & TP73-AS1 & TP73 antisense RNA 1 & \\
\hline & YME1L1 ${ }^{a}$ & YME1 like 1 ATPase & Alzheimer's disease \\
\hline
\end{tabular}

apreviously associated with several neurodegenerative diseases (identified using GCBI online software), but not PD

${ }^{\mathrm{b}}$ Previously associated with PD (identified using GCBI online software)

Fig. 4). In blood, these processes such as protein amino acid phosphorylation (9 genes), regulation of neuron maturation (1 gene), positive regulation of neuron maturation (1 gene) are highly related to neuron. SRPK2 and MAP2K6 are found to be involved in PD [33, 34]. BCL2 was reported in Alzheimer's Disease [35]. In brain 
Table 3 Common differentially expressed genes identified from substantia nigra in PD patients and healthy controls, and PDspecific and other neurodegenerative diseases related genes identification

\begin{tabular}{|c|c|c|c|}
\hline Expression & Gene symbol & Gene name & $\begin{array}{l}\text { Corresponding neurodegenerative } \\
\text { disease other than PD }\end{array}$ \\
\hline \multirow[t]{11}{*}{ Down-regulated } & CARHSP $1^{a}$ & calcium regulated heat stable protein 1 & Multiple sclerosis \\
\hline & GART $^{a}$ & $\begin{array}{l}\text { phosphoribosylglycinamide formyltransferase } \\
\text { phosphoribosylglycinamide synthetase, } \\
\text { phosphoribosylaminoimidazole synthetase }\end{array}$ & Alzheimer's disease \\
\hline & MUC4 & mucin 4 , cell surface associated & \\
\hline & $\mathrm{NIN}$ & ninein & \\
\hline & $N R F 1^{a}$ & nuclear respiratory factor 1 & Alzheimer's disease \\
\hline & PRELPa & $\begin{array}{l}\text { proline and arginine rich end leucine rich } \\
\text { repeat protein }\end{array}$ & $\begin{array}{l}\text { Nervous system disease; } \\
\text { Neurodegenerative disease }\end{array}$ \\
\hline & RGS12 & regulator of G-protein signaling 12 & \\
\hline & RNF130 & ring finger protein 130 & Motor neuron disease \\
\hline & SNAP $23^{a}$ & synaptosome associated protein 23 & Nervous system disease \\
\hline & SNTB2 & syntrophin beta 2 & \\
\hline & TBX1 & T-box 1 & \\
\hline \multirow[t]{6}{*}{ Up-regulated } & ACSL6 $6^{a}$ & acyl-CoA synthetase long-chain family member 6 & Nervous system disease \\
\hline & $\mathrm{ATP}^{\mathrm{a}} \mathrm{S}^{\mathrm{a}}$ & $\begin{array}{l}\text { ATP synthase, } \mathrm{H}+\text { transporting, mitochondrial } \\
\text { Fo complex subunit } \mathrm{s} \text { (factor B) }\end{array}$ & Alzheimer's disease \\
\hline & CADPS & calcium dependent secretion activator & \\
\hline & $\mathrm{DCLK} 1^{\mathrm{a}}$ & doublecortin like kinase 1 & Alzheimer's disease \\
\hline & PPFIA2 & PTPRF interacting protein alpha 2 & \\
\hline & SNCA & synuclein alpha & \\
\hline
\end{tabular}

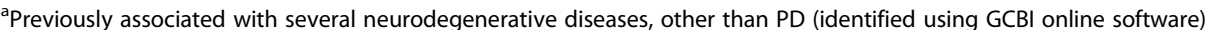

bPreviously associated with PD (PD-specific) (identified using GCBI online software)

$\mathrm{SN}$, negative regulation of neurotransmitter uptake $(1$ gene) and negative regulation of catecholamine uptake involved in synaptic transmission (1 gene) are highly related to neuron. SNCA is reported to be in PD [36]. All these information validate our finding regarding the association of these genes in PD.

\section{PPI network construction for common DEGs}

PPI networks were constructed using STRING v.10.5 database and then visualized and analyzed by Cytoscape software v.3.4.0. The PPI information obtained from STRING online software for common DEGs in blood is demonstrated in Additional file 1: Table S3 and the PPI network is shown in Fig. 5a. Here, the 29 genes exhibited a wide degree distribution with the highest degree of 18 and lowest degree of 1 .The average degree value was found to be 6.14. Finally, the top three hub genes(i. e. top $10 \%$ of the total nodes) with higher degree were chosen, including ATM, MGAM and BCL2 genes. Out of the three hubs, one hub (BCL2) was already found to be related to Alzheimer's Disease [35], which was further studied for their association in human PD. The PPI information obtained from STRING online software for common DEGs in brain SN is exhibited in Additional file 1: Table S4 and the PPI network is shown in Fig. 5b.
We found that highest degree value was 3 and the lowest was 1 with an average of 1.69 . In this analysis, the top three hub genes with higher degree included GART, SNCA and NIN genes. SNCA hub node was already found to be associated with human PD [36], and GART hub node has been verified in other neurodegenerative diseases such as Alzheimer's Disease [37], but not in PD.

\section{Regulatory miRNAs associated with the common PD- specific genes and the analysis of IncRNAs associated with these miRNAs}

To investigate the regulation of the $\mathrm{PD}$-specific genes identified in our study by non-coding RNAs, miRNA associated with these genes were first retrieved from DIANA-Tarbase v.7.0 database, and then lncRNAs associated with these miRNAs were selected from DIANALncBase Experimentally v.2 (prediction score $\geq 0.90$ ). The biological regulatory interaction of PD-specific genes identified in blood is exhibited in Table 4, which shows that four PD-specific genes were associated with several non-coding RNAs. Out of the miRNAs, 13 were previously known to be associated with several other neurodegenerative diseases, such as Alzheimer's disease and nine were also previously associated with PD. The biological regulatory interaction of PD-specific genes 


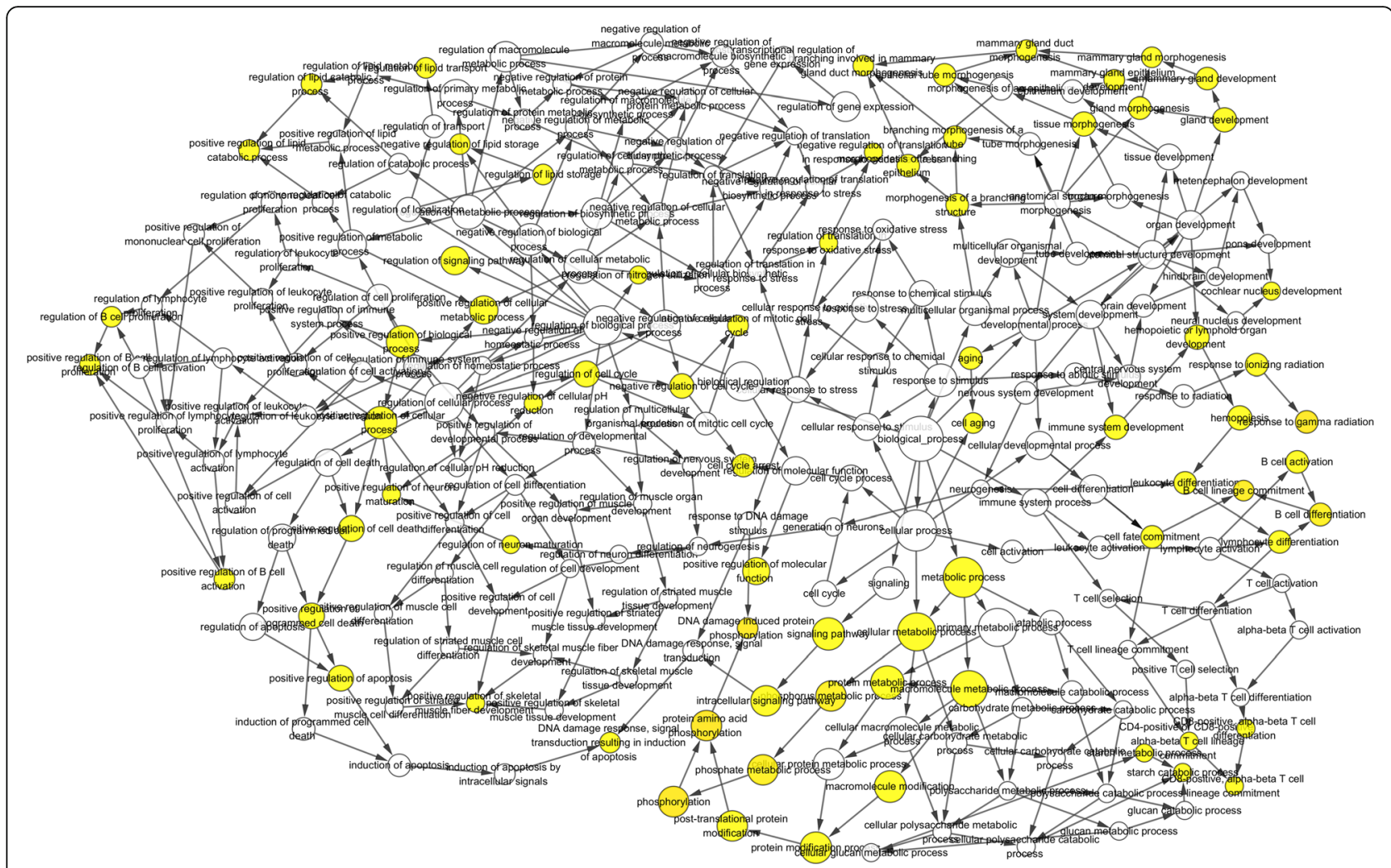

Fig. $3 \mathrm{GO}$ biological processes network of diferentially expressed genes in blood of Parkinson's Disease from BiNGO software. Large nodes indicate more genes involved in. Yellow nodes: $P$-value $<0.05$ and FDR $<0.05$

identified in brain SN is showed in Table 5, which demonstrates that one PD-specific gene was associated with several non-coding RNAs. Out of the miRNAs, one was previously known to be associated with other neurodegenerative diseases and five were also previously associated with $\mathrm{PD}$. Out of these five, four PD-specific genes (HSPA6, SRPK2, NOL7 and SNCA) were associated with miRNAs that were previously associated with PD. Moreover, most of these miRNAs associated with PD-specific genes were in turn regulated by lncRNAs. Among the miRNAs, 14 has been previously associated with neurodegenerative diseases, and 14 were previously associated with PD.

\section{mTF-miRNA-gene-gTF regulatory network construction of PD-specific genes}

To further study the regulatory mechanism of these common PD-specific genes (the genes from Tables 2 and 3 that were defined as PD-specific by authors) in PD pathogenesis, we constructed a regulatory network comprising common PD-specific genes, the TFs associated with these genes (gTFs), miRNAs associated with these genes and the TFs associated with these miRNAs (mTFs). Additional file 1: Table S5 and Fig. 6 show the
mTF-miRNA-gene-gTF regulatory networks identified in blood. Additional file 1: Table S6 and Fig. 7 show the mTF-miRNA-gene-gTF regulatory networks identified in brain $\mathrm{SN}$.

\section{IncRNAs and mTFs associated with these PD-specific miRNAs related to the PD-specific genes}

The 14 PD-specific miRNAs shown in Tables 4 and 5 (hsa-miR-204-3p, hsa-miR-17-3p, hsa-miR-181a-5p, hsamiR-181b-5p, hsa-miR-181c-5p, hsa-miR-181d, hsa-miR19a-3p, hsa-miR-19b-3p, hsa-miR-93-3p, hsa-miR-153, hsa-miR-23b-3p, hsa-miR-34a-5p, hsa-miR-9-5p and hsa-miR-7-5p) were further analyzed in the DIANALncBase Experimental v.2 database to examine the regulatory information of miRNAs-lncRNAs (Table 6) and in the TransmiR v.1.2 database to examine the regulatory information of miRNAs-mTFs. The 14 miRNAs were found to be associated with 45 lncRNAs. These 14 miRNAs control four PD-specific genes in our study, and these miRNAs are in turn regulated by $31 \mathrm{mTFs}$ (Table 6). By combining all the regulatory information obtained from our results, we constructed a regulatory pattern involving the PD-specific miRNAs, lncRNAs, PD-specific genes and mTFs. 


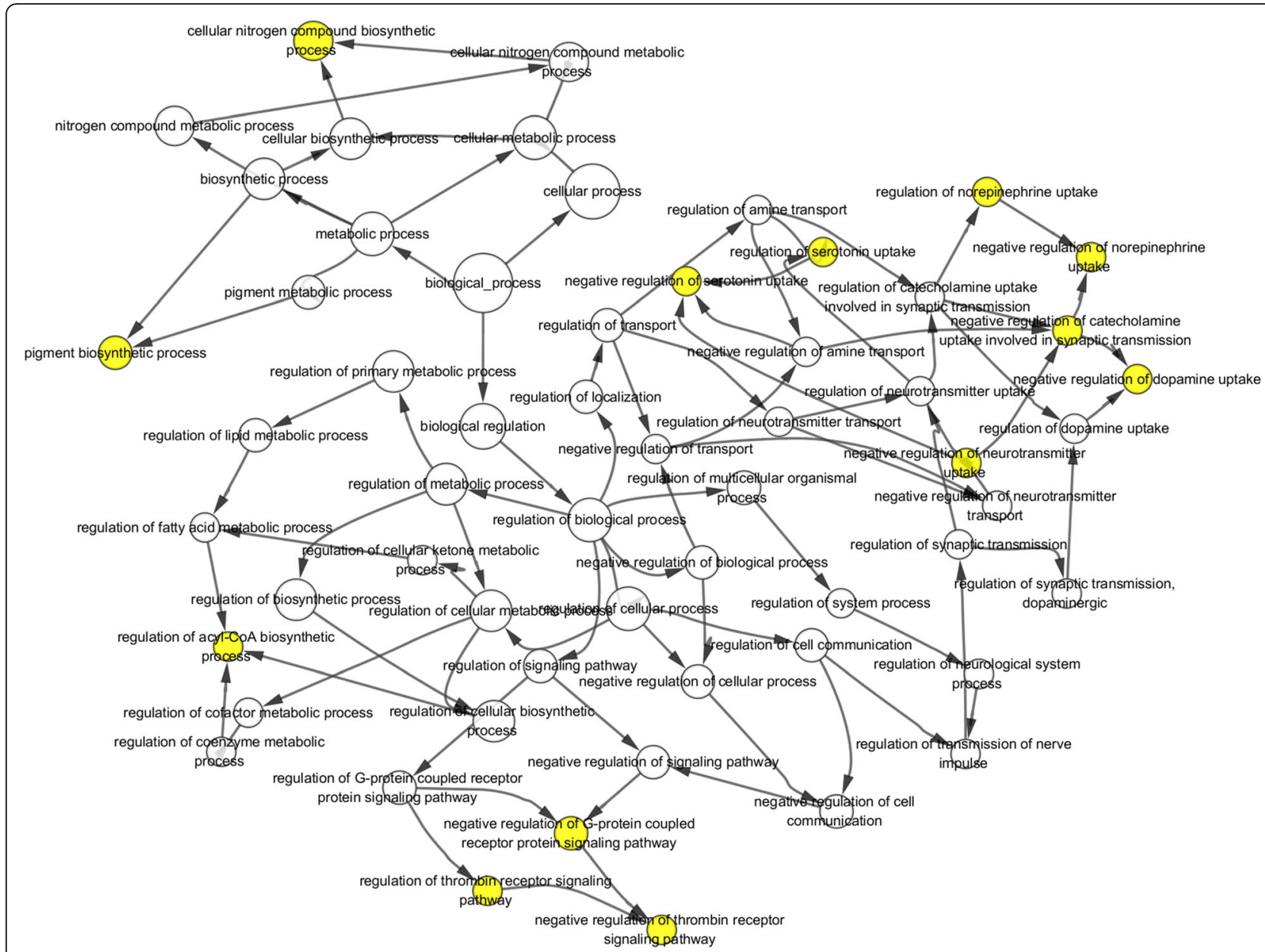

Fig. $4 \mathrm{GO}$ biological processes network of diferentially expressed genes in substantia nigra of Parkinson's Disease from BiNGO software. Large nodes indicate more genes involved in. Yellow nodes: P-value $<0.05$ and FDR $<0.05$

mTF-miRNA-gene-gTF regulatory analysis of the common non-PD-specific genes

To study the regulatory interaction of the common nonPD-specific genes, we got mTF-miRNA-gene-gTF regulatory patterns from blood (Additional file 1: Table S7) and brain SN (Additional file 1: Table S8) respectively. We obtained 359 gTFs (score $=1$ ) that were related to 26 common DEGs from blood datasets. The TCF3, BAZ1A and THOC2 genes were regulated by the highest numbers of gTFs (105, 95 and 95 gTFs, respectively). Previous reports showed TCF3 involvement in PD [38]. TCF3, a transcriptional repressor [39], is counteracted at multiple levels by Wnt signaling [40]. Alteration in normal Wnt signaling pathway has been already found in gene expression studies of blood of PD patients [40]. It was found that BAZ1A depletion influence the expression of genes important for nervous system development and function [41]. THOC2, an abundant protein in the developing and mature human $[42,43]$ and adult mouse brains [44]. THOC2 depletion has been already reported to stimulate neurite outgrowth in primary rat hippocampal neurons [44]. It has been identified also to be involved in neoplasms and multiple sclerosis [45, 46].

The common non-PD-specific genes were associated with 100 experimentally validated miRNAs. Out of these miRNAs, 25 were previously known to be associated with PD (Table 7). The NCOA3, AKAP13 and BCL2 genes were regulated by the highest numbers of miRNAs (21, 19 and 14 miRNAs, respectively). NCOA3, a nuclear receptor coactivator, has been reported to play an important role in some biological processes, such as cell proliferation and apoptosis [47]. Previous study indicate that high expression of NCOA3 can suppress cells apoptosis induced by histone deacetylase inhibitor in breast cancer [47]. BCL2, an anti-apoptotic gene, regulate cell death (apoptosis), by either inducing or inhibiting apoptosis. The observed upregulation of BCL2 by GDNF suggests that BCL2 protects neurons, possibly by regulating cell apoptosis. Previous studys have shown its alteration in Alzheimer's Disease [35]. AKAP13 protein functions 


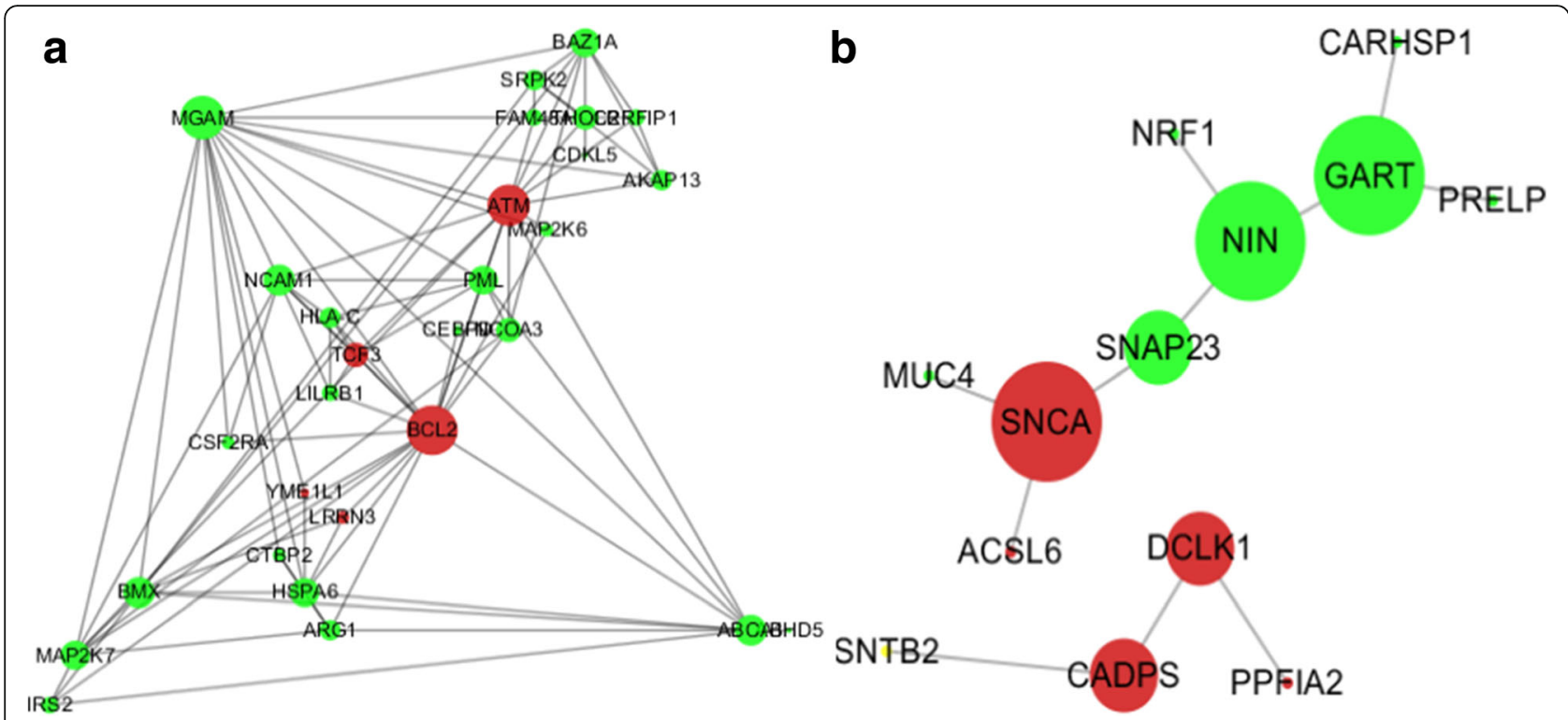

Fig. 5 PPI networks obtained from Cytoscape software. a PPI network for common genes from blood; $\mathbf{b}$ PPI network for common genes from the brain substantia nigra region. Red nodes represent upregulated genes, and green nodes represent downregulated genes. Large nodes indicate bigger degrees

as an anchor protein for the regulatory subunit of protein kinase A which is reported to increase tau phosphorylation. AKAP13 are likely more specifically involved in tau phosphorylation pathways that is highly related to Alzheimer's disease [48, 49]. Out of these three genes, NCOA3 was associated with hsa-let-7 g-5p, hsa-miR-106b-5p, hsa-miR-17-5p, hsa-miR-181c-5p, hsamiR-20a-5p, hsa-miR-25-3p and hsa-miR-27b-3p that were reported to be previously known to be associated with PD (Table 7). AKAP13 was associated with hsamiR-34a-5p, and hsa-miR-34c-5p that were reported to be previously known to be associated with PD (Table 7). BCL2 was associated with hsa-miR-132-5p, hsa-miR182-5p, hsa-miR-23b-3p and hsa-miR-34a-5p that were reported to be previously known to be associated with PD (Table 7). Overall, the 100 miRNAs were identified to be associated with 98 mTFs.

In brain SN, 333 gTFs were associated with 14 common genes. The NIN, PPFIA2 and ATP5S genes were regulated by the highest numbers of gTFs (139, 102 and 93 gTFs, respectively). NIN, a large coiled-coil protein, is essential for neurogenesis, angiogenesis and stem cell fate [50]. Previous study showed that alternative splicing in NIN gene appears sufficient for neural stem cells differentiation into neurons [50]. PPFIA2 is a member of the leukocyte common antigen-related PTP interacting protein family liprin [47]. It is known to be downregulated by androgens in prostate cancer cell lines [47] and is found to play crucial functions in the pathophysiology of schizophrenia and bipolar disorder [51]. ATP5S gene encodes a subunit of mitochondrial ATP synthase which utilizes the electro chemical gradient to synthetize ATP from ADP in inner mitochondrial membrane by oxidative phosphorylation [52]. Mitochondrial dysfunction is reported to be a pathological pathway associated with PD [53]. But little is known about the involvement of ATP5S in PD.

The common non-PD-specific genes were associated with 50 experimentally validated miRNAs. Out of these miRNAs, 16 were previously known to be associated with PD (Table 7). It was found that NIN and SNTB2 were regulated by the highest numbers of miRNAs (18 and 25 miRNAs, respectively), and that NIN and SNTB2 were associated with 16 miRNAs (such as miR-9-5p) (Table 7) that were previously associated with PD. For example, in study, miR-9-5p increased by more than three times in treated PD patients compared with those of controls [54]. Moreover, miR-9-5p were in turn regulated by mTFs of interleukin 1 beta (IL1B) and nuclear factor kappa B subunit 1 (NFKB1). Genetic variation in the proinflammatory cytokine gene IL1B can contribute to risk of developing PD. These finding supported that miR-9-5p may contributes to the pathogenesis of sporadic PD. Previous finding reported SNTB2 involved in atherosclerosis [55], and that its risk factors in atherosclerosis include higher plasma urate level [56] which has linked to lower risk of PD in men [57]. Overall, the 50 miRNAs were identified to be associated with 63 mTFs.

These data support the finding that these genes may be significant factors in PD, but furture studys are needed. 
Table 4 Regulatory miRNAs associated with the common PD-specific genes identified in blood and the analysis of IncRNAs associated with these miRNAs

\begin{tabular}{|c|c|c|}
\hline PD specific genes & miRNAs associated with genes & IncRNAs associated with the miRNAs \\
\hline \multirow[t]{2}{*}{ HSPA6 } & hsa-miR-204-3p & LINC00999 \\
\hline & hsa-miR-548o-3p & CASC7, GABPB1-AS1, NEAT1, XIST \\
\hline \multirow[t]{8}{*}{ MAP2K6 } & hsa-miR-33a-5p a & KCNQ1OT1, MCF2L-AS1 \\
\hline & hsa-miR-590-3p $p^{a}$ & $\begin{array}{l}\text { CASC7, CTA-292E10.9, CTB-89H12.4, HCG11, } \\
\text { LINC00657, LOC100507577, NEAT1, } \\
\text { OIP5-AS1, OTUD6B-AS1, RP11-834C11.4, XIST }\end{array}$ \\
\hline & hsa-miR-145-5 $p^{a}$ & KCNQ1OT1,TUG1 \\
\hline & hsa-miR-425-5p & $\begin{array}{l}\text { C1orf132, CTD-3025 N20.3, KCNQ1OT1, } \\
\text { RP11-15H20.7, SNHG14, TTTY15, ZNRD1-AS1 }\end{array}$ \\
\hline & hsa-miR-1306-5p & KCNQ1OT1, SENP3-EIF4A1 \\
\hline & hsa-miR-148a-3pa & CASC7, KCNQ1OT1, OIP5-AS1, SNHG14 \\
\hline & hsa-miR-130a-3p a & CASC7, H19, SNHG14 \\
\hline & hsa-miR-148b-3p a & CASC7, OIP5-AS1, SLMO2-ATP5E, SNHG14 \\
\hline \multirow[t]{19}{*}{ SRPK2 } & hsa-miR-3200-3p & BLOC1S5-TXNDC5, KCNQ1OT1, XIST \\
\hline & hsa-miR-1292 & \\
\hline & hsa-miR-155-5p & CTD-2561 J22.5, RP11-175O19.4, XIST \\
\hline & hsa-miR-15b-3pa & \\
\hline & hsa-miR-17-3p b & RP3-323A16.1, XIST \\
\hline & hsa-miR-181a-5p & $\begin{array}{l}\text { AC000403.4, CASC7, CTB-89H12.4, KCNQ1 OT1, } \\
\text { LINC00506, N4BP2L2-IT2, RP11-10E18.7, RP11-1134114.8, } \\
\text { RP11-147 L13.14, RP11-314B1.2, RP11-361F15.2, } \\
\text { RP11-707A18.1, RP1-309122.2, ZNF883, ZNRD1-AS1 }\end{array}$ \\
\hline & hsa-miR-181b-5p & CASC7, CTB-89H12.4, KCNQ1OT1, RP11-1134|14.8, XIST \\
\hline & hsa-miR-181c-5p & CTB-89H12.4, KCNIP4-IT1, KCNQ1OT1, RP11-1134|14.8 \\
\hline & hsa-miR-181d ${ }^{b}$ & \\
\hline & hsa-miR-183-3pa & \\
\hline & hsa-miR-1976 & HNRNPUL2-BSCL2, KCNQ1 OT1, LOC100129917, NEAT1, TSIX \\
\hline & hsa-miR-19a-3p ${ }^{b}$ & $\begin{array}{l}\text { FAM201A, H19, KCNA3, KCNQ1OT1, LINC00094, RP11-337C18.8, } \\
\text { RP11-523G9.3, SNHG14 }\end{array}$ \\
\hline & hsa-miR-19b-3p ${ }^{b}$ & $\begin{array}{l}\text { CASC7, FAM201A, H19, KCNA3, KCNQ1OT1, LINC00094, } \\
\text { RP11-337C18.8, RP11-523G9.3, SNHG14 }\end{array}$ \\
\hline & hsa-miR-21-5p $p^{a}$ & \\
\hline & hsa-miR-320a & $\begin{array}{l}\text { ALMS1-IT1, CASC7, CTB-36H16.2, CTB-89H12.4, KCNIP4-IT1, } \\
\text { LINC00663, LMCD1-AS1, MALAT1, NEAT1, RP11-145P16.3, XIST }\end{array}$ \\
\hline & hsa-miR-3685 & KCNQ1OT1 \\
\hline & hsa-miR-3689a-3p & TTY15 \\
\hline & hsa-miR-4518 & \\
\hline & hsa-miR-944 & \\
\hline \multirow[t]{8}{*}{ NOL7 } & hsa-miR-199b-3pa & CTB-89H12.4, ERVK3-1, XIST \\
\hline & hsa-miR-199a-3p b & CTB-89H12.4, ERVK3-1, XIST \\
\hline & hsa-miR-328 & \\
\hline & hsa-miR-129-5 $p^{a}$ & CASC7, ERVK3-1, KCNQ1OT1, MALAT1, NEAT1, \\
\hline & hsa-miR-374a-5p $p^{a}$ & $\begin{array}{l}\text { CTC-444 N24.11, CTD-2561 J22.5, RP11-613D13.5, TRG-AS1, } \\
\text { XIST, ZNRD1-AS1 }\end{array}$ \\
\hline & hsa-miR-744-5p & FLJ16779, \\
\hline & hsa-miR-374b-5p $p^{a}$ & $\begin{array}{l}\text { CTA-292E10.9, CTC-444 N24.11, OIP5-AS1, RP11-221 J22.1, } \\
\text { RP11-38P22.2, XIST, }\end{array}$ \\
\hline & hsa-miR-548o-3p & CASC7, GABPB1-AS1, NEAT1, XIST, \\
\hline
\end{tabular}


Table 5 Regulatory miRNAs associated with the common PD-specific genes identified in substantia nigra and the analysis of IncRNAs associated with these miRNAs

\begin{tabular}{|c|c|c|}
\hline Genes associated with PD & miRNAs associated with genes & IncRNAs associated with the miRNAs \\
\hline \multirow[t]{8}{*}{ SNCA } & hsa-miR-93-3p & AC012065.7,KCNQ1OT1, LINC00342 \\
\hline & hsa-miR-153 ${ }^{b}$ & \\
\hline & hsa-miR-23b-3p b & $\begin{array}{l}\text { CASC7,CTC-459F4.3, KCNQ1OT1, RP11-215G15.5, } \\
\text { SNHG14, TOB1-AS1, XIST, ZNRD1-AS1 }\end{array}$ \\
\hline & hsa-miR-500a-5p & SNHG22 \\
\hline & hsa-miR-34a-5p & $\begin{array}{l}\text { AC004951.6, AC092535.3, KCNQ1OT1, LINC00662, } \\
\text { PCBP2-OT1, RP11-693 J15.5 }\end{array}$ \\
\hline & hsa-miR-29a-3pa & $\begin{array}{l}\text { AC005154.6, H19, KCNQ1OT1, LINC00674, MIR4697HG, } \\
\text { NEAT1, RP11-314B1.2, RP11-582E3.6, RP4-630A11.3, } \\
\text { THUMPD3-AS1, TTTY15, TUG1 }\end{array}$ \\
\hline & hsa-miR-7-5 $p^{b}$ & $\begin{array}{l}\text { AC005154.6, DLX6-AS1, KCNQ1OT1, LINC01233, } \\
\text { LINC01314, RP11-679B19.1, XIST }\end{array}$ \\
\hline & hsa-miR-181a-2-3p & KCNQ1OT1, NEAT1 \\
\hline
\end{tabular}

apreviously associated with several neurodegenerative diseases, but not PD

${ }^{b}$ Previously associated with PD

\section{SNP analysis of the common PD-specific and other neurodegenerative disease-specific genes}

We next obtained SNPs corresponding to the common DEGs (both the PD-specific and the neurodegenerative disease-specific genes) of our study from the online databases MirSNP, miRdSNP and LincSNP 2.0. Six miRNAs were found to be associated with two PD-specific SNPs corresponding to the PDspecific gene SNCA (Table 8). Two SNPs were associated with these six miRNAs (Table 8). The chromosome locus and allele gene for these two SNPs were then searched using the dbSNP database. These two SNPs were located on chromosome 4.

Twenty-three miRNAs were found to be associated with seven neurodegenerative disease-specific SNPs corresponding to four neurodegenerative disease-specific genes (Table 9). Seven SNPs were associated with these 23 miRNAs. The chromosome locus and allele gene for these seven SNPs were then searched using the dbSNP database. The chromosome loci of these SNPs include 6, 14,16 and 18.

\section{Discussion}

\section{Meta-analysis of common genes}

In the past decades, microarray has been widely used to identify DEGs and pathways underlying PD pathogenesis. In these studies, most microarray datas are mainly from the brain regions or blood in PD. The analysis of this brain regions from PD may only highlight genes associated with changes in cellular composition [58], However, brain tissues are not easily obtained. In recent years, there is evidence to prove that low concentrations of urate in the blood serum increased the risk of PD [12], and that there is a growing interest in the discovery of blood biomarkers for PD. Some genes have been proved to take part in important neurodegeneration molecular pathways in PD patients.

A large number of microarray gene expression studies on PD have been performed, but some of the results showed low consistency among involved genes and pathways. Meta-analysis has suggested new biological insights, as well as identification of greater consistent genes and pathways potential in PD pathogenesis [13, $15,16]$. Numbers of meta-analysis on PD have been conducted, with few focused on understanding the regulatory network involving genes, miRNAs, transcription factors (TFs) and lncRNA in PD progression. Moreover, few meta-analysis on PD is focused on comparative analysis of microarray datases profiles from brain and blood samples.

In our study, meta-analysis merges several datasets from PD brain SN or blood into a single analysis to obtain more meaningful set of DEGs and these DEGs are analyzed in various biogenetic databases to get related non-coding RNAs and gTFs, among others. In this study of DEGs in PD patients compared with healthy controls, we identified 36 common DEGs in blood studies and 17 common DEGs in five brain SN studies using metaanalysis technique-Vote counting generic ways. Of the total common genes, 28 genes were previously reported as associated with other neurodegenerative diseases (see Tables 2 and 3), but not previously known to be associated with $\mathrm{PD}$, and five genes were previously shown to be associated with PD. Among the 28 genes associated with other neurodegenerative diseases, 22 were downregulated and six were upregulated in $\mathrm{PD}$ compared with controls. We further studied these 28 genes for their association with PD. Out of the five genes previously associated with PD, three genes (HSPA6, MAP2K6 and SRPK2 genes) were downregulated and two genes 


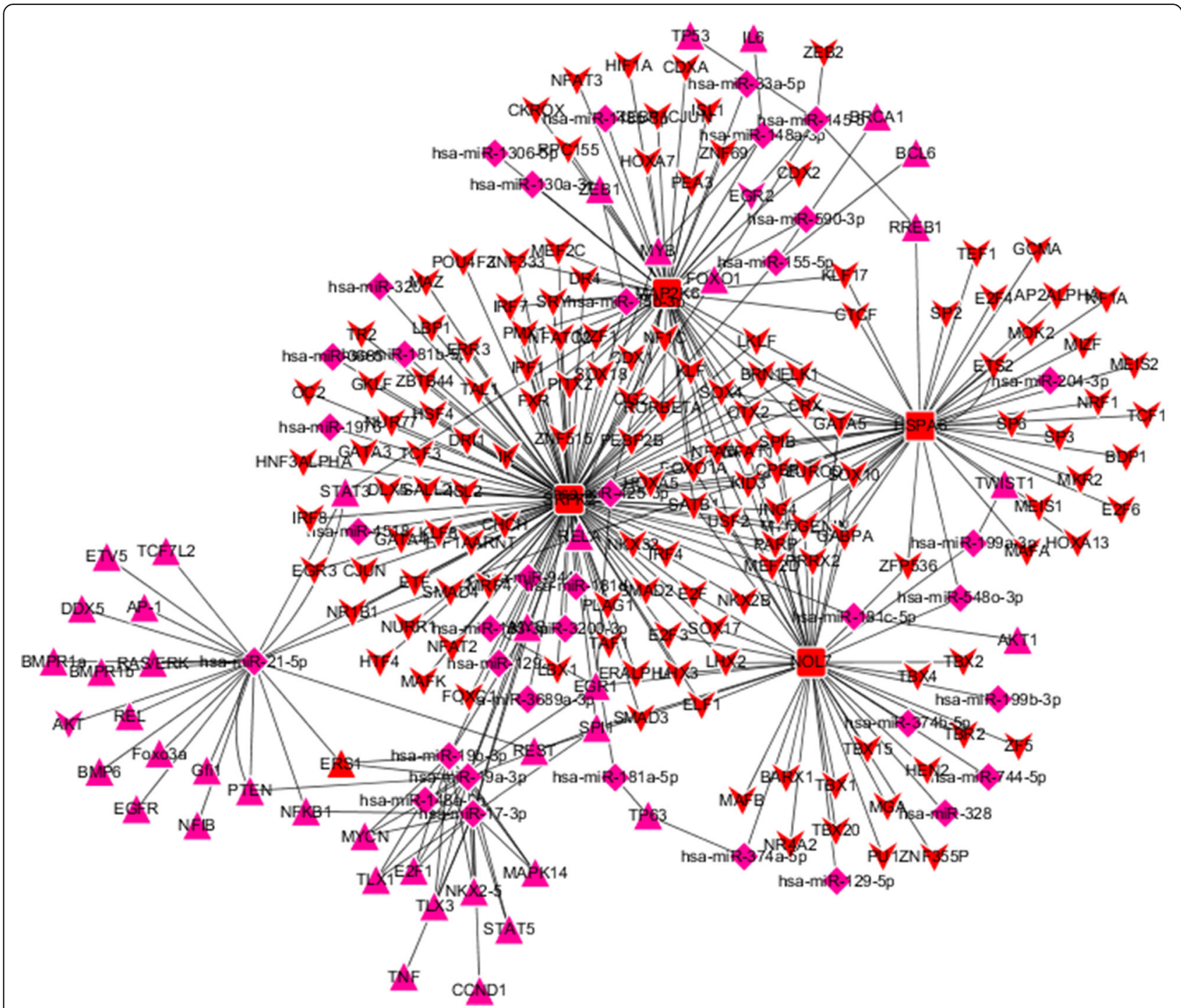

Fig. 6 The mTF-miRNA-gene-gTF regulatory network of PD-specific genes identified in blood datasets obtained from Cytoscape software. The diamond-shaped magenta nodes represent miRNAs, the triangle-shaped magenta nodes represent transcription factors (TFs) associated with these miRNAs (mTFs), and the round rectangle-shaped red nodes represent the PD-specific genes. The V-shaped red nodes represent the TFs associated with these genes (gTFs)

(NOL7 and SNCA genes) were upregulated in PD compared with controls. A recent study reported the role of HSPA6 in SH-SY5Y neuronal cells which are used as a model system for neurodegenerative diseases such as Alzheimer's disease and PD [59]. HSPA6, aslo known as Hsp70B', is a member of heat shock proteins (Hsps) 70 family and the Hsp70 family of heat shock proteins has been well known for its roles in cytoprotective effects against cell death and implicated in neuroprotection [59]. It was also found that HSPA6 has previously been examined in human neurodegenerative diseases and was proposed as a potential treatment strategy to counter PD [60]. Studies have found that MAP2K6 binds to and regulates the expression of the $\mathrm{PD}$-related protein LRRK2, which is a prevalent cause of sporadic PD [33]. SRPK2, a serine/arginine protein-specific kinase, is highly expressed in the brain. Increased amounts of SRPK2 can lead to the hyperphosphorylation of serinearginine-rich proteins, which in turn induces changes in alternative pre-mRNA splicing observed in PD [34]. NOL7 is a candidate cancer suppressor that localizes to $6 \mathrm{p} 23$, a segment with frequent loss of heterozygosity $(\mathrm{LOH})$ in many tumors [61]. NOL7 interacts with amyloid precursor protein (APP) protein which accumulates in mitochondrial membrane in PD, and that APP interacts with LRRK2 and then is phosphorylated at Thr668 


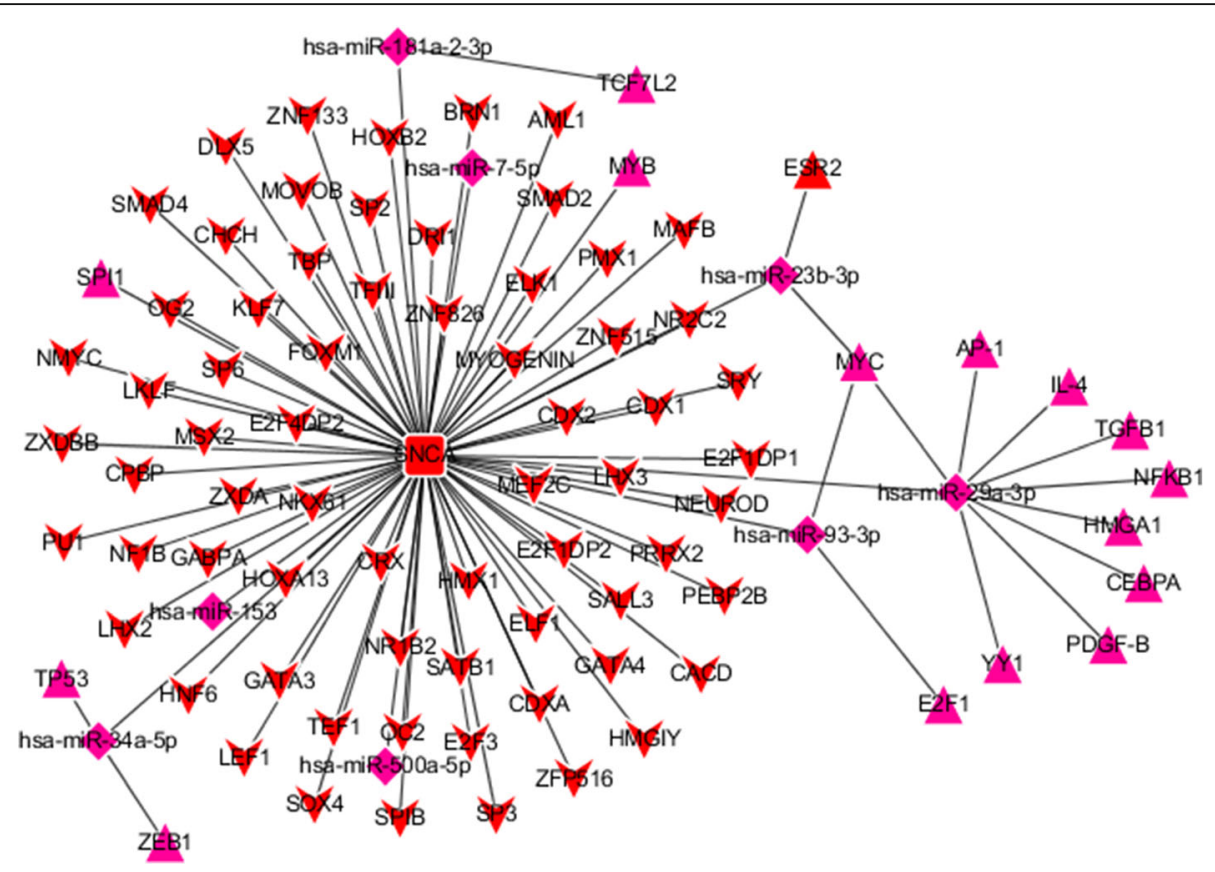

Fig. 7 The mTF-miRNA-gene-gTF regulatory network of PD-specific genes identified in substantia nigra datasets obtained from Cytoscape software. The diamond-shaped magenta nodes represent miRNAs, the triangle-shaped magenta nodes represent transcription factors (TFs) associated with these miRNAs (mTFs), and the round rectangle-shaped red nodes represent the PD-specific genes. The V-shaped red nodes represent the TFs associated with these genes ( $g T F s$ )

within its intracellular domain to promote neurotoxicity in PD [62]. SNCA was reported to be associated with $\mathrm{PD}$, and different SNPs in the SNCA gene had a correlation with increased or decreased risk of PD [63]. All these data help validate our results showing an association of these genes in PD.

Moreover, our study screen the overlapped genes among common DEGs obtained from two different tissues (brain SN and blood), but did not get any common genes. And It was found that the common DEGs from blood and brain $\mathrm{SN}$ are enriched in different BP.

The analysis of IncRNAs and mTFs associated with these PD-specific miRNAs related to the PD-specific genes

The biological regulations of the common PD-specific genes are shown in Tables 4 and 5 . We examined the relevance of experimentally validated miRNAs and lncRNAs with these five PD genes. Our analysis showed that four out of the five PD-specific genes (HSPA6, SRPK2, NOL7 and SNCA) are regulated by 14 PDspecific miRNAs (Tables 4 and 5). Interestingly, SRPK2 (obtained from blood) was regulated by the highest number of PD-specific miRNAs (hsa-miR-17-3p, hsamiR-181a-5p, hsa-miR-181b-5p, hsa-miR-181c-5p, hsamiR-181d, hsa-miR-19a-3p and hsa-miR-19b-3p) and these seven PD-specific miRNAs are regulated by 25 lncRNAs and 16 mTFs (Table 6).

\section{mTF-miRNA-gene-gTF regulatory network analysis}

In this study, we screened the overlapped gTFs of PDspecific and non-PD-specific genes mTF-miRNA-genegTF regulatory network obtained from blood studies. Result showed that 135 gTFs are found to be involved in these two networks. It was found that core promoter element-binding protein (CPBP), Spi-B transcription factor (SPIB) and KID3 are the gTFs, which regulated a maximum number of genes, 28,27 and 24 genes respectively. The CPBP was associated with four PDspecific genes (HSPA6, MAP2K6, SRPK2 and NOL7) and 24 non-PD-specific genes as obtained from TRANSFAC database [27]. SPIB was found to be associated with four PD-specific genes(HSPA6, MAP2K6, SRPK2 and NOL7) and 23 non-PD-specific genes. KID3 was found to be associated with four PD-specific genes(HSPA6, MAP2K6, SRPK2 and NOL7) and 20 non-PD-specific genes in GeneCards database (http://www.genecards. org/). CPBP is reported to be with lung cancer [64] and SPIB is found to be associated with leukemia cells [65]. Previous study reported that KID3 was to be highly expressed in adult brain [66]. These three gTFs are not reported previously to be associated with $\mathrm{PD}$. But they regulate the four $\mathrm{PD}$-specific genes and many non-PDspecific genes from blood.

In PD-specific and non-PD-specific genes mTFmiRNA-gene-gTF regulatory network obtained from brain SN studies, 59 overlapped gTFs is found to be 
Table 6 The IncRNA-mediated PD-specific miRNAs associated the PD-specific mRNAs identified in our study regulatory network

\begin{tabular}{|c|c|c|c|c|}
\hline Tissue & $\begin{array}{l}\text { PD-specific } \\
\text { miRNA }\end{array}$ & IncRNAs associated the miRNAs & $\begin{array}{l}\text { the PD-specific } \\
\text { mRNAs associated } \\
\text { the miRNA }\end{array}$ & TFs associated with the miRNAs \\
\hline \multirow[t]{9}{*}{ Blood } & hsa-miR-204-3p & LINC00999 & HSPA6 & \\
\hline & hsa-miR-17-3p & RP3-323A16.1, XIST & SRPK2 & $\begin{array}{l}\text { Activation:CCND1,E2F1,MYC, MYCN, } \\
\text { NKX2-5, TLX1, TLX3, TNF, ERS1, STAT5; } \\
\text { Repression: NFKB1, SPI1; Neutral: MAPK14 }\end{array}$ \\
\hline & $\begin{array}{l}\text { hsa-miR-181a- } \\
5 p\end{array}$ & $\begin{array}{l}\text { AC000403.4, CASC7, CTB-89H12.4, } \\
\text { KCNQ1OT1, LINC00506, N4BP2L2-IT2, } \\
\text { RP11-10E18.7, RP11-1134114.8, } \\
\text { RP11-147 L13.14, RP11-314B1.2, } \\
\text { RP11-361F15.2, RP11-707A18.1, } \\
\text { RP1-309I22.2, ZNF883, ZNRD1-AS1 }\end{array}$ & SRPK2 & Neutral: TP63 \\
\hline & $\begin{array}{l}\text { hsa-miR-181b- } \\
5 p\end{array}$ & $\begin{array}{l}\text { CASC7, CTB-89H12.4, KCNQ1OT1, } \\
\text { RP11-1134114.8, XIST }\end{array}$ & SRPK2 & \\
\hline & $\begin{array}{l}\text { hsa-miR-181c- } \\
5 p\end{array}$ & $\begin{array}{l}\text { CTB-89H12.4, KCNIP4-IT1, KCNQ1OT1, } \\
\text { RP11-1134I14.8 }\end{array}$ & SRPK2 & Activation: AKT1 \\
\hline & hsa-miR-181d & & SRPK2 & \\
\hline & hsa-miR-19a-3p & $\begin{array}{l}\text { FAM201A, H19, KCNA3, KCNQ1OT1, } \\
\text { LINC00094, RP11-337C18.8, RP11-523G9.3, } \\
\text { SNHG14 }\end{array}$ & SRPK2 & $\begin{array}{l}\text { Activation: E2F1, MYC, MYCN, NKX2-5, } \\
\text { TLX1, TLX3, ERS1, STAT5; Repression:SPI1; } \\
\text { Neutral:PTEN, MAPK14 }\end{array}$ \\
\hline & hsa-miR-19b-3p & $\begin{array}{l}\text { CASC7, FAM201A, H19, KCNA3, KCNQ1OT1, } \\
\text { LINC00094, RP11-337C18.8, RP11-523G9.3, } \\
\text { SNHG14 }\end{array}$ & SRPK2 & $\begin{array}{l}\text { Activation: E2F1, MYC, MYCN, NKX2-5, } \\
\text { TLX1, TLX3, ERS1; } \\
\text { Neutral: MAPK14 }\end{array}$ \\
\hline & $\begin{array}{l}\text { hsa-miR-199a- } \\
3 p\end{array}$ & CTB-89H12.4, ERVK3-1, XIST & NOL7 & Neutral: TWIST1 \\
\hline \multirow[t]{5}{*}{$\begin{array}{l}\text { Substantia } \\
\text { nigra }\end{array}$} & hsa-miR-93-3p & AC012065.7,KCNQ1OT1, LINC00342 & SNCA & $\begin{array}{l}\text { Repression: MYC; } \\
\text { Neutral: E2F1 }\end{array}$ \\
\hline & hsa-miR-153 & & SNCA & \\
\hline & hsa-miR-23b-3p & $\begin{array}{l}\text { CASC7,CTC-459F4.3, KCNQ1OT1, } \\
\text { RP11-215G15.5, SNHG14, TOB1-AS1, } \\
\text { XIST, ZNRD1-AS1 }\end{array}$ & SNCA & $\begin{array}{l}\text { Repression: MYC; } \\
\text { Neutral: ESR2 }\end{array}$ \\
\hline & hsa-miR-34a-5p & $\begin{array}{l}\text { AC005154.6, H19, KCNQ1OT1, LINC00674, } \\
\text { MIR4697HG, NEAT1, RP11-314B1.2, } \\
\text { RP11-582E3.6, RP4-630A11.3, THUMPD3-AS1, } \\
\text { TTTY15, TUG1 }\end{array}$ & SNCA & $\begin{array}{l}\text { Activation: HMGA1, AP-1; } \\
\text { Repression: MYC, NFKB1, YY1, IL-4, PDGF-B, } \\
\text { TGFB1; } \\
\text { Neutral: CEBPA }\end{array}$ \\
\hline & hsa-miR-7-5p & $\begin{array}{l}\text { CTB-89H12.4, KCNQ1OT1, RP11-273G15.2, } \\
\text { RP11-314B1.2, RP11-793H13.8, SNHG14, } \\
\text { TSNAX-DISC1, TUG1 }\end{array}$ & SNCA & $\begin{array}{l}\text { Activation: NFKB1, IL1B, TLR2, TLR4, TLR7, } \\
\text { TLR8, TNF, MYC, NFKB1; } \\
\text { Repression: TLX }\end{array}$ \\
\hline
\end{tabular}

involved in these two networks. CPBP, caudal type homeobox 1(CDX1) and SPIB are the gTFs, which regulated maximum genes i.e. 13, 12 and 12 genes, respectively. All three gTFs were found to regulate the PDspecific gene SNCA and 12, 11, and 11 non-PD-specific genes respectively.

The overlapped gTFs were filtered out in PD-specific regulatory patterns from blood and brain $\mathrm{SN}$ and 42 gTFs were screened. CPBP and SPIB are the gTFs, which regulated a maximum number of genes, 5 PD-specific genes(HSPA6, MAP2K6, SRPK2, NOL7 and SNCA) respectively.

Finally, we screened the overlapped gTFs in non-PDspecific regulatory patterns from blood and brain $\mathrm{SN}$, 236 gTFs were identified. CPBP, KID3 and SPIB are the
gTFs, which regulated maximum genes i.e. 36,34 and 34 genes.

Combination of above results, we supposed that CPBP and SPIB may play significant roles in PD. But there is no verification of experiments. So further researches are needed.

Next, analysis of these miRNAs associated with PDspecific genes and non-PD-specific genes resulted in the identification of common PD-specific miRNAs (hsamiR-181c-5p, hsa-miR-23b-3p and hsa-miR-34a-5p). Hsa-miR-181c-5p was shown to regulate PD-specific gene SRPK2 from blood (shown in Table 4) and regulate non-PD-specific gene NCOA3 from blood (Table 7). Hsa-miR-23b-3p is found to regulate PD-specific gene SNCA from brain SN (shown in Table 4), and regulate 
Table 7 miRNAs that are previously known to be associated with PD associated with non-PD-specific genes identified in our study

\begin{tabular}{|c|c|c|c|}
\hline miRNAs from blood & $\begin{array}{l}\text { mRNA targets associated } \\
\text { with the miRNAs }\end{array}$ & miRNAs from substantia nigra & $\begin{array}{l}\text { mRNA targets associated } \\
\text { with the miRNAs }\end{array}$ \\
\hline hsa-let-7 g-5p & NCOA3 & hsa-let-7a-5p & SNAP23 \\
\hline hsa-let-7i-5p & IRS2 & hsa-let-7e-5p & SNAP23 \\
\hline hsa-miR-101-5p & $\mathrm{TMX} 4$ & hsa-miR-106a-5p & $\mathrm{NIN}$ \\
\hline hsa-miR-106a-5p & NCOA3 & hsa-miR-106b-5p & NIN \\
\hline hsa-miR-106b-5p & ABHD5, NCOA3 & hsa-miR-125a-5p & $\mathrm{NIN}$ \\
\hline hsa-miR-125a-5p & MAP2K7 & hsa-miR-17-5p & SNTB2 \\
\hline hsa-miR-132-3p & ATM & hsa-miR-182-5p & SNTB2 \\
\hline hsa-miR-132-5p & $\mathrm{BCL} 2$ & hsa-miR-20a-5p & NIN \\
\hline hsa-miR-143-3p & FAM102A & hsa-miR-23b-3p & NIN, SNTB2 \\
\hline hsa-miR-17-5p & ABHD5, NCOA3 & hsa-miR-25-3p & SNTB2 \\
\hline hsa-miR-181c-5p & NCOA3 & hsa-miR-302d-5p & SNTB2 \\
\hline hsa-miR-182-5p & $\mathrm{BCL} 2$ & hsa-miR-30a-5p & SNTB2 \\
\hline hsa-miR-18a-5p & ATM & hsa-miR-30e-5p & SNTB2 \\
\hline hsa-miR-20a-5p & ABHD5, NCOA3 & hsa-miR-93-5p & SNTB2 \\
\hline hsa-miR-212-3p & LRRFIP1 & hsa-miR-9-5p & SNTB2 \\
\hline hsa-miR-214-3p & FAM120A & & \\
\hline hsa-miR-23b-3p & $\mathrm{BCL} 2$ & & \\
\hline hsa-miR-25-3p & NCOA3 & & \\
\hline hsa-miR-27a-3p & ABCA1, FAM102A, FAM120A & & \\
\hline hsa-miR-27b-3p & NCOA3 & & \\
\hline hsa-miR-30e-5p & IRS2 & & \\
\hline hsa-miR-34a-5p & AKAP13, ATM, BCL2 & & \\
\hline hsa-miR-34c-5p & AKAP13 & & \\
\hline hsa-miR-363-3p & IRS2 & & \\
\hline hsa-miR-93-5p & $\mathrm{ABCA} 1, \mathrm{ABHD} 5$ & & \\
\hline
\end{tabular}

non-PD-specific gene BCL2 from blood and NIN and SNTB2 from brain SN (Table 7). It was found that hsamiR-34a-5p regulate PD-specific gene SNCA from brain SN (shown in Table 4), and regulate non-PD-specific gene AKAP13, ATM and BCL2 from blood and SNTB2 from brain SN (Table 7). Maybe, these three common miRNAs play an important role in PD, but further study is needed.

The biological regulations of the common PD-specific genes are shown in Tables 4 and 5 . We examined the relevance of experimentally validated miRNAs and lncRNAs with these five PD genes. Our analysis showed that four out of the five PD-specific genes (HSPA6, SRPK2, NOL7 and SNCA) are regulated by 14 PDspecific miRNAs (Tables 4 and 5). Interestingly, SRPK2 was regulated by the highest number of PD-specific miRNAs (hsa-miR-17-3p, hsa-miR-181a-5p, hsa-miR181b-5p, hsa-miR-181c-5p, hsa-miR-181d, hsa-miR-19a$3 p$ and hsa-miR-19b-3p) and these seven PD-specific miRNAs are regulated by 25 lncRNAs and 16 mTFs (Table 6).

\section{Identification of feed forward loops from mTF-miRNA- gene-gTF regulatory networks}

Analysis of the regulatory network of PD-specific genes identified in blood datasets revealed the presence of two interesting feed-forward loops (FFLs), in which a TF regulates a miRNA and in turn they both regulate a target gene. One FFL was detected among the SPRK2 gene, hsa-miR-19a-3p and Spi-1 proto-oncogene (SPI1). The TransmiR information indicated that hsa-miR-19a-3p is inhibited by the SPI1 TF. By combing the TransmiR and DIANA-Tarbase data, we found that SPI1 and hsa-miR19a-3p both regulate the expression of its target gene SPRK2. Studies have found that SPI1 plays an important role in the regulation of genes related to the function of microglia, which accumulate in PD [67]. Another study revealed that lower SPI1 expression reduces risk for AD by regulating myeloid gene expression and cell function [68]. Another study revealed a function of miR-19a in multiple system atrophy, which is a sporadic neurodegenerative disease, identifying lower expression of this miRNA in multiple system atrophy patients than 
controls [69]. Moreover, previous study reported the association of downregulated levels of miR-19a in idiopathic Parkinson's disease (IPD) [70]. This information provides functional insights into the finding of downregulation of hsa-miR-19a-3p by SPI1. However, the FFL gene SPRK2 was identified downregulated in our study.

The other FFL is among the SPRK2 gene, hsa-miR-17$3 p$ and SPI1. The TransmiR information indicated that hsa-miR-17-3p is inhibited by the SPI1 TF. By combing the TransmiR and DIANA-Tarbase data, we found that SPI1 and hsa-miR-17-3p both regulate the expression of its target gene SPRK2. Another study showed that miR17 is upregulated in multiple system atrophy [71] and reduced during neurogenesis [72]. By combining this information, we elucidated possible relationships among the genes, miRNAs and TFs in FFLs in neurodegenerative disease by using Cytoscape software v. 3.4.0 (Fig. 8). Further study on these FFLs may help us understand the molecular biology of PD.

\section{Significance of IncRNAs and mTFs associated with these PD-specific miRNAs related to the PD-specific genes}

The network showed the relationship among the PDspecific miRNAs, mTFs and lncRNAs. In this regulatory network, we identified 45 lncRNAs associated with these PD-specific miRNAs. The regulations of $31 \mathrm{mTFs}$ associated with 14 PD-specific miRNAs showed that most of these interactions had an activating effect (Table 6). The regulation of hsa-miR-204-3p of this network is noteworthy. It is associated with one lncRNAs but has no mTFs associated with it (Table 6). This miRNA represses HSPA6 which is known to be involved in PD [59]. In contrast to the above findings, hsa-miR-181a-5p has a maximum number of lncRNAs (15 lncRNAs) associated with it (Table 6). This miRNA is in turn repress one gene namely SRPK2. This gene is known to be involved in PD [34]. However, the miRNA is associated with only one mTFs (TP63) (Table 6). In order to find out the functional role of these 45 lncRNAs, we further analyzed them in EVLncRNAs database (http://biophy.dzu.edu. cn/EVLncRNAs/) [73]. Two lncRNAs (NEAT1 and TUG1) were found to be associated with neurodegenerative disease. Nuclear paraspeckle assembly transcript 1 (NEAT1) is known to be involved in neurological disorders including amyotrophic lateral sclerosis [74] and Huntington's disease [75]. Taurine up-regulated 1 (TUG1) is known to be involved in neurological disorders including Huntington's disease [76]. But their functions in PD were not identified by previous studies.Since these two lncRNAs of this regulatory network are associated with PD-specific miRNAs of our study, they might play an important role in PD.

\section{Significance of SNP analysis of the common PD-specific and other neurodegenerative disease-specific genes}

Two SNPs were identified to be associated with the SNCA gene (shown in Table 8), which is in turn controlled by miRNAs including the PD-specific miRNA hsa-miR-153. The dbSNP database showed that SNCA is located on chromosome 4. SNPs rs17016074 and rs356165 are location in the SNCA gene, which is related to PD $[77,78]$. Table 8 shows that these two SNPs are identified to be associated with SNCA gene which is in turn controlled by PD-specific miRNA hsa-miR-153 and this finding was experimentally validated [77, 78]. This strengthens the association of these two SNPs in PD. In addition, SNPs rs17016074 and rs356165 in SNCA gene associated with hsa-miR-7 is involved in PD and it was experimentally validated. However, hsa-miR-7 was not previously linked with PD. Therefore, hsa-miR-7 may be a significant PD epigenetic biomarker that requires further study.

We also analyzed SNPs associated with several neurodegenerative disease-specific genes that are in turn controlled by several miRNAs(shown in Table 9). Twentythree SNPs were identified from four neurodegenerative

Table 8 SNPs in PD with associated PD-specific genes and miRNAs

\begin{tabular}{|c|c|c|c|c|c|c|}
\hline MicroRNAs & SNPS & Allele & Chromosome & Gene & MinorAlleleCount & Experimentally_confirmed \\
\hline hsa-miR-141 & rs17016074 & $A / G$ & 4:89726127 & SNCA & $A=0.0503 / 252$ & \\
\hline hsa-miR-153 & rs17016074 & $A / G$ & & SNCA & & Yes \\
\hline hsa-miR-223 & rs17016074 & $A / G$ & & SNCA & & \\
\hline hsa-miR-499-3p & rs17016074 & $A / G$ & & SNCA & & \\
\hline hsa-miR-504 & rs17016074 & $A / G$ & & SNCA & & \\
\hline hsa-miR-7 & rs17016074 & $A / G$ & & SNCA & & Yes \\
\hline hsa-miR-141 & rs356165 & $A / G$ & 4:89725735 & SNCA & $A=0.4842 / 2425$ & \\
\hline hsa-miR-153 & rs356165 & $A / G$ & & SNCA & & Yes \\
\hline hsa-miR-223 & rs356165 & $A / G$ & & SNCA & & \\
\hline hsa-miR-504 & rs356165 & $A / G$ & & SNCA & & \\
\hline hsa-miR-7 & rs356165 & $A / G$ & & SNCA & & Yes \\
\hline
\end{tabular}


Table 9 SNPs with their associated miRNAs and genes in neurodegenerative diseases other than PD

\begin{tabular}{|c|c|c|c|c|c|c|c|}
\hline MicroRNAs & SNPs & Allele & Chromosome & Gene & MinorAlleleCount & Region & $\begin{array}{l}\text { SNPs related diseases by } \\
\text { experimentally_confirmed }\end{array}$ \\
\hline hsa-miR-4428 & rs1049853 & $\mathrm{C} / \mathrm{T}$ & $6: 31269123$ & HLA-C & $A=0.0903 / 452$ & $3^{\prime} \mathrm{UTR}$ & $\begin{array}{l}\text { Alzheimer's disease, Rheumatoid } \\
\text { arthritis }\end{array}$ \\
\hline hsa-miR-27a-5p & rs1016860 & $\mathrm{A} / \mathrm{G}$ & 18:63127841 & BCL2 & $T=0.1166 / 584$ & $3^{\prime} U T R$ & \multirow[t]{6}{*}{ Multiple sclerosis } \\
\hline hsa-miR-3127-5p & rs1016860 & $A / G$ & 18:63127841 & BCL2 & $T=0.1166 / 584$ & $3^{\prime} U T R$ & \\
\hline hsa-miR-3158-3p & rs1016860 & $A / G$ & 18:63127841 & $\mathrm{BCL} 2$ & $\mathrm{~T}=0.1166 / 584$ & 3'UTR & \\
\hline hsa-miR-4720-3p & rs1016860 & $A / G$ & 18:63127841 & $\mathrm{BCL} 2$ & $T=0.1166 / 584$ & $3^{\prime} \mathrm{UTR}$ & \\
\hline hsa-miR-4789-5p & rs1016860 & $A / G$ & 18:63127841 & $\mathrm{BCL} 2$ & $T=0.1166 / 584$ & $3^{\prime} U T R$ & \\
\hline hsa-miR-629-5p & rs1016860 & $A / G$ & 18:63127841 & $\mathrm{BCL} 2$ & $T=0.1166 / 584$ & 3'UTR & \\
\hline hsa-miR-1224-5p & rs1058929 & $\mathrm{A} / \mathrm{G} / \mathrm{T}$ & 16:8853394 & CARHSP1 & $C=0.4740 / 2374$ & $3^{\prime} U T R$ & \multirow[t]{6}{*}{ Alzheimer's disease } \\
\hline hsa-miR-1265 & rs1058929 & $\mathrm{A} / \mathrm{G} / \mathrm{T}$ & 16:8853394 & CARHSP1 & $C=0.4740 / 2374$ & 3'UTR & \\
\hline hsa-miR-3605-5p & rs1058929 & $\mathrm{A} / \mathrm{G} / \mathrm{T}$ & 16:8853394 & CARHSP1 & $C=0.4740 / 2374$ & $3^{\prime} U T R$ & \\
\hline hsa-miR-3915 & rs1058929 & $\mathrm{A} / \mathrm{G} / \mathrm{T}$ & 16:8853394 & CARHSP1 & $C=0.4740 / 2374$ & 3'UTR & \\
\hline hsa-miR-4710 & rs1058929 & $\mathrm{A} / \mathrm{G} / \mathrm{T}$ & 16:8853394 & CARHSP1 & $C=0.4740 / 2374$ & $3^{\prime} U T R$ & \\
\hline hsa-miR-5585-5p & rs1058929 & $\mathrm{A} / \mathrm{G} / \mathrm{T}$ & 16:8853394 & CARHSP1 & $C=0.4740 / 2374$ & $3^{\prime} U T R$ & \\
\hline hsa-miR-193a-5p & rs9953 & $\mathrm{G} / \mathrm{T}$ & 16:8853271 & CARHSP1 & $G=0.4507 / 2257$ & $3^{\prime} U T R$ & \multirow{3}{*}{$\begin{array}{l}\text { Alzheimer's disease, } \\
\text { glioblastoma }\end{array}$} \\
\hline hsa-miR-3190-3p & rs9953 & $\mathrm{G} / \mathrm{T}$ & 16:8853271 & CARHSP1 & $G=0.4507 / 2257$ & $3^{\prime} U T R$ & \\
\hline hsa-miR-3615 & rs9953 & $\mathrm{G} / \mathrm{T}$ & 16:8853271 & CARHSP1 & $G=0.4507 / 2257$ & $3^{\prime} U T R$ & \\
\hline hsa-miR-335-5p & rs1058967 & $A / G$ & 16:8853179 & CARHSP1 & $C=0.4744 / 2376$ & $3^{\prime} U T R$ & \multirow[t]{4}{*}{ Alzheimer's disease } \\
\hline hsa-miR-451b & rs1058967 & $A / G$ & 16:8853179 & CARHSP1 & $C=0.4744 / 2376$ & $3^{\prime} \mathrm{UTR}$ & \\
\hline hsa-miR-4533 & rs1058967 & $A / G$ & 16:8853179 & CARHSP1 & $C=0.4744 / 2376$ & $3^{\prime} U T R$ & \\
\hline hsa-miR-4797-5p & rs1058967 & $A / G$ & $16: 8853179$ & CARHSP1 & $C=0.4744 / 2376$ & 3'UTR & \\
\hline hsa-miR-3679-3p & rs2447924 & $\mathrm{G} / \mathrm{T}$ & $16: 8854616$ & CARHSP1 & $C=0.4754 / 2381$ & $3^{\prime} U T R$ & \multirow[t]{2}{*}{ Alzheimer's disease } \\
\hline hsa-miR-4286 & rs2447924 & $\mathrm{G} / \mathrm{T}$ & $16: 8854616$ & CARHSP1 & $C=0.4754 / 2381$ & 3'UTR & \\
\hline hsa-miR-4517 & rs8017316 & $C / G$ & 14:50322860 & ATP5S & $G=0.4511 / 2259$ & Intron & Alzheimer's disease \\
\hline
\end{tabular}

disease-specific genes. HLA-C was found to be located on chromosome 6 and several previous studies have found the function of HLA-C in multiple sclerosis that was activated by killer cell immunoglobulin like receptor, two Ig domains and long cytoplasmic tail 2(KIR2DL2) [79]. The SNP rs1049853 in HLA-C was identified in

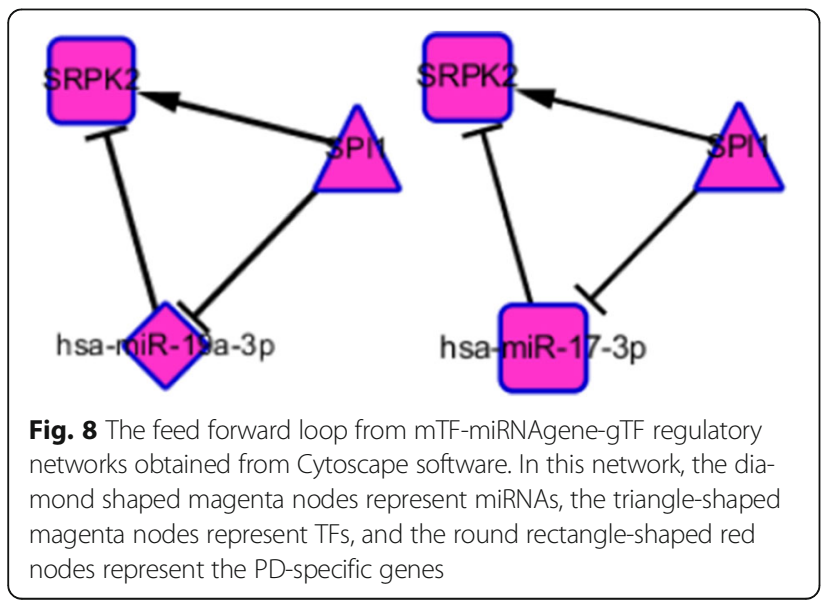

multiple sclerosis patients and was controlled by the miRNA hsa-miR-4428. BCL2 is located on chromosome 18; SNP rs1016860 is located in the BCL2 gene, and the two possible nucleotide variations (A or G) are considered alleles for this base position. This SNP is regulated by several miRNAs: hsa-miR-27a-5p, hsa-miR-3127-5p, hsa-miR-3158-3p, hsa-miR-4720-3p, hsa-miR-4789-5p and hsa-miR-629-5p. MiR-27a was previously shown to be involved in neurodegenerative diseases, such as Huntington's disease and Alzheimer disease [80, 81]. MiR3127 and miR-629 were shown to play a role in cancer $[82,83]$. CARHSP1 is located on chromosome 16 and there are four SNPs (rs1058929, rs9953, rs1058967 and rs2447924) at this specific base position; three possible nucleotide variations (A, G or T) are considered alleles for the rs1058929 base position, two possible nucleotide variations ( $G$ or $T)$ are considered alleles for rs9953 and rs2447924 base positions, and two possible nucleotide variations ( $G$ or $A$ ) are considered alleles for the rs1058967 base position. These four SNPs may be regulated by several miRNAs: hsa-miR-1224-5p, hsa-miR1265, hsa-miR-3605-5p, hsa-miR-3915, hsa-miR-4710, 
hsa-miR-5585-5p, hsa-miR-193a-5p, hsa-miR-3190-3p, hsa-miR-3615, hsa-miR-335-5p, hsa-miR-451b, hsa-miR4533, hsa-miR-4797-5p, hsa-miR-3679-3p and hsa-miR4286. MiR-1224 was found the fountion in PD targeting LRRK2 [84]. MiR-1265, miR-193a, miR-3615, miR-335 and miR-4286 were shown to play a role in cancer [8588]. Two SNPs, rs6430498 and rs12512664, in miR-3679 were significantly associated with femoral neck bone mineral density [89]. Therefore, future studies should pursue the function of these SNPs and associated miRNAs in PD disease.

\section{Conclusion}

In this study, we performed a meta-analysis with three microarray datasets from PD blood studies and five from PD SN studies to study DEGs, gene regulatory networks and lncRNA-mediated regulatory networks. The metaanalysis identified 36 common DEGs in PD blood studies and 17 common DEGs in PD SN studies. Further, we identified five PD-specific genes in our study: HSPA6, MAP2K6, SRPK2, NOL7 and SNCA genes. Analysis of the regulatory miRNAs associated with the common PD-specific genes resulted in the identification of PDspecific miRNAs (hsa-miR-204-3p, hsa-miR-17-3p, hsamiR-181a-5p, hsa-miR-181b-5p, hsa-miR-181c-5p, hsamiR-181d, hsa-miR-19a-3p, hsa-miR-19b-3p, hsa-miR93-3p, hsa-miR-153, hsa-miR-23b-3p, hsa-miR-34a-5p, hsa-miR-9-5p and hsa-miR-7-5p). Analysis of the mTFmiRNA-gene-gTF network also led to the identification of two FFLs: one FFL between the SPRK2 gene, hsamiR-19a-3p and SPI1 and the other between the SPRK2 gene, hsa-miR-17-3p and SPI. In the lncRNA-mediated regulatory network, 45 lncRNAs were associated with known PD-specific miRNAs in our study. Notably, these were not identified in previous studies and warrant further investigation as they might be important epigenetic regulators in PD. Moreover, SNP analysis identified two significant SNPs associated with PD-specific genes and six regulatory miRNAs, and seven significant SNPs associated with other neurodegenerative disease-specific genes and 23 regulatory miRNAs. These SNPs could be considered as latent risk factors for further validation. Thus, the findings of our study should be explored in further investigation of PD.

\section{Additional file}

Additional file 1: Table S1. GO biological processes analysis of diferentially expressed genes in blood of Parkinson's Disease. Table S2. GO biological processes analysis of diferentially expressed genes in substantia nigra of Parkinson's Disease. Table S3. The PPI information for common DEGs in blood obtained from STRING online software. Table S4. The PPI information for common DEGs in substantia nigra obtained from STRING online software. Table S5. The mTF-miRNA-gene-gTF regulatory network of common PD-specific genes identified in blood datasets.
Table S6. The mTF-miRNA-gene-gTF regulatory network of common PD-specific genes identified in brain substantia nigra. Table S7. The mTF-miRNA-gene-gTF regulatory network of common genes identified in blood datasets(other than PD-specific genes). Table $\mathbf{5 8}$. The mTF-miRNAgene-gTF regulatory network of common genes identified in substantia nigra datasets(other than PD-specific genes). (XLS $1121 \mathrm{~kb}$ )

\section{Abbreviations}

BP: Biological processes; DE: Differentially expressed; FFL: Feed forward loop; gTF: Gene transcription factor; HC: Healthy control; IncRNA: Long non-coding RNA; miRNA: microRNA; mTF: microRNA transcription factor; PD: Parkinson's disease; PPI: Protein protein interaction; SN: Substantia nigra; SNP: Single nucleotide polymorphism; TF: Transcription factor

\section{Acknowledgements}

We thank Edanz Group (www.edanzediting.com/ac) for editing a draft of this manuscript.

\section{Funding}

This work was supported by the Key Project of Hebei North University (No. 120177), science and technology bureau research development plan of zhangjiakou city in Hebei (No. 0911021D-4) and the Science and Technology Research Project of Hebei Province Department Institutions of Higher Learning (No. Z2015047), China.

\section{Availability of data and materials}

All the data supporting the findings of this study are contained in the manuscript and the corresponding supplementary files.

\section{Authors' contributions}

LS and HW designed the study, LS, CW, CZ, HW and XS performed the data analysis, and LS wrote the manuscript. HW supervised this work. All authors read and approved the final manuscript.

\section{Ethics approval and consent to participate}

Not applicable.

\section{Consent for publication \\ Not applicable.}

\section{Competing interests}

The authors declare that they have no competing interests.

\section{Publisher's Note}

Springer Nature remains neutral with regard to jurisdictional claims in published maps and institutional affiliations.

\section{Author details}

${ }^{1}$ Department of Biology of Basic Medical Science College, Hebei North University, Zhangjiakou 075000, Hebei, China. ' ${ }^{2}$ Department of Basic Medicine, Zhangjiakou University, Zhangjiakou 75000, Hebei, China. ${ }^{3}$ Shenzhen RealOmics (Biotech) Co., Ltd, Shenzhen 518081, Guangdong, China.

Received: 19 December 2017 Accepted: 26 March 2018 Published online: 13 April 2018

\section{References}

1. Jankovic J. Parkinson's disease: clinical features and diagnosis. J Neurol Neurosurg Psychiatry. 2008;79(4):368-76. https://doi.org/10.1136/jnnp.2007. 131045.

2. Davie CA. A review of Parkinson's disease. Br Med Bull. 2008;86:109-27. https://doi.org/10.1093/bmb/ldn013.

3. Goldman SM. Environmental toxins and Parkinson's disease. Annu Rev Pharmacol Toxicol. 2014;54:141-64. https://doi.org/10.1146/annurevpharmtox-011613-135937.

4. Samii A, Nutt JG, Ransom BR. Parkinson's disease. Lancet. 2004;363(9423): 1783-93.

5. Lesage S, Brice A. Parkinson's disease: from monogenic forms to genetic susceptibility factors. Hum Mol Genet. 2009;18(R1):R48-59. https://doi.org/ 10.1093/hmg/ddp012. 
6. Kalia LV, Lang AE. Parkinson's disease. Lancet. 2015;386(9996):896-912. https://doi.org/10.1016/S0140-6736(14)61393-3.

7. Dhungel N, Eleuteri S, Li LB, Kramer NJ, Chartron JW, Spencer B, Kosberg K, Fields JA, Stafa K, Adame A, et al. Parkinson's disease genes VPS35 and EIF4G1 interact genetically and converge on alpha-synuclein. Neuron. 2015; 85(1):76-87. https://doi.org/10.1016/j.neuron.2014.11.027.

8. Funayama M, Hasegawa K, Kowa H, Saito M, Tsuji S, Obata F. A new locus for Parkinson's disease (PARK8) maps to chromosome 12p11.2-q13.1. Ann Neurol. 2002;51(3):296-301.

9. Fu R, Cui SS, Du JJ, He YC, Gao C, Huang P, Qian YW, Luo XG, Chen SD. Fatigue correlates with LRRK2 G2385R variant in Chinese Parkinson's disease patients. Parkinsonism Relat Disord. 2017;44:101-5. https://doi.org/10.1016/j. parkreldis.2017.09.016.

10. Berge-Seidl V, Pihlstrom L, Maple-Grodem J, Forsgren L, Linder J, Larsen JP, Tysnes OB, Toft M. The GBA variant E326K is associated with Parkinson's disease and explains a genomewide association signal. Neurosci Lett. 2017; 658:48-52. https://doi.org/10.1016/j.neulet.2017.08.040.

11. Martins M, Rosa A, Guedes LC, Fonseca BV, Gotovac K, Violante S, Mestre T, Coelho M, Rosa MM, Martin ER, et al. Convergence of miRNA expression profiling, alpha-synuclein interacton and GWAS in Parkinson's disease. PLoS One. 2011;6(10):e25443. https://doi.org/10.1371/journal.pone.0025443.

12. Chahine LM, Stern MB, Chen-Plotkin A. Blood-based biomarkers for Parkinson's disease. Parkinsonism Relat Disord. 2014;20(Suppl 1):S99-103. https://doi.org/10.1016/S1353-8020(13)70025-7.

13. Chatterjee P, Roy D, Bhattacharyya M, Bandyopadhyay S. Biological networks in Parkinson's disease: an insight into the epigenetic mechanisms associated with this disease. BMC Genomics. 2017;18(1):721. https://doi.org/10.1186/ s12864-017-4098-3.

14. Mariani E, Frabetti F, Tarozzi A, Pelleri MC, Pizzetti F, Casadei R. Meta-Analysis of Parkinson's disease transcriptome data using TRAM software: Whole substantia nigra tissue and single dopamine neuron differential gene expression. PLoS One. 2016;11(9):e0161567. https://doi.org/10.1371/journal. pone.0161567.

15. Chang D, Nalls MA, Hallgrimsdottir IB, Hunkapiller J, van der Brug M, Cai F Kerchner GA, Ayalon G, Bingol B, Sheng M, et al. A meta-analysis of genome-wide association studies identifies 17 new Parkinson's disease risk loci. Nat Genet. 2017;49(10):1511-6. https://doi.org/10.1038/ng.3955.

16. Wang Q, Li WX, Dai SX, Guo YC, Han FF, Zheng JJ, Li GH, Huang JF. MetaAnalysis of Parkinson's disease and Alzheimer's disease revealed commonly impaired pathways and dysregulation of NRF2-dependent genes. J Alzheimers Dis. 2017;56(4):1525-39. https://doi.org/10.3233/JAD-161032.

17. Hong F, Breitling R, McEntee CW, Wittner BS, Nemhauser JL, Chory J. RankProd: a bioconductor package for detecting differentially expressed genes in meta-analysis. Bioinformatics. 2006;22(22):2825-7.

18. Das S, Ghosal S, Sen R, Chakrabarti J. InCeDB: database of human long noncoding RNA acting as competing endogenous RNA. PLoS One. 2014; 9(6):e98965. https://doi.org/10.1371/journal.pone.0098965.

19. Davis S, Meltzer PS. GEOquery: a bridge between the Gene Expression Omnibus (GEO) and BioConductor. Bioinformatics. 2007;23(14):1846-7.

20. Dweep H, Gretz N, Sticht C. miRWalk database for miRNA-target interactions. Methods Mol Biol. 2014;1182:289-305. https://doi.org/10.1007/ 978-1-4939-1062-5_25.

21. Ramasamy A, Mondry A, Holmes CC, Altman DG. Key issues in conducting a meta-analysis of gene expression microarray datasets. PLoS Med. 2008;5(9): e184. https://doi.org/10.1371/journal.pmed.0050184.

22. Maere S, Heymans K, Kuiper M. BiNGO: a Cytoscape plugin to assess overrepresentation of gene ontology categories in biological networks. Bioinformatics. 2005;21(16):3448-9.

23. von Mering C, Huynen M, Jaeggi D, Schmidt S, Bork P, Snel B. STRING: a database of predicted functional associations between proteins. Nucleic Acids Res. 2003;31(1):258-61.

24. Kohl M, Wiese S, Warscheid B. Cytoscape: software for visualization and analysis of biological networks. Methods Mol Biol. 2011;696:291-303. https:// doi.org/10.1007/978-1-60761-987-1_18.

25. Paraskevopoulou MD, Vlachos IS, Hatzigeorgiou AG. DIANA-TarBase and DIANA Suite Tools: Studying Experimentally Supported microRNA Targets. Curr Protoc Bioinformatics. 2016;55:12.14.1-18. https://doi.org/ 10.1002/cpbi.12.

26. Paraskevopoulou MD, Georgakilas G, Kostoulas N, Reczko M, Maragkakis M, Dalamagas TM, Hatzigeorgiou AG. DIANA-LncBase: experimentally verified and computationally predicted microRNA targets on long non-coding
RNAs. Nucleic Acids Res. 2013;41(Database issue):D239-45. https://doi.org/ 10.1093/nar/gks1246.

27. Fogel GB, Weekes DG, Varga G, Dow ER, Craven AM, Harlow HB, Su EW, Onyia JE, Su C. A statistical analysis of the TRANSFAC database. Biosystems. 2005;81(2):137-54

28. Wang J, Lu M, Qiu C, Cui Q. TransmiR: a transcription factor-microRNA regulation database. Nucleic Acids Res. 2010;38(Database issue):D119-22. https://doi.org/10.1093/nar/gkp803.

29. Bruno AE, Li L, Kalabus JL, Pan Y, Yu A, Hu Z. miRdSNP: a database of disease-associated SNPS and microRNA target sites on 3'UTRs of human genes. BMC Genomics. 2012;13:44. https://doi.org/10.1186/1471-2164-13-44.

30. Shi $Y$, Yang $F$, Wei $S, X u$ G. Identification of key genes affecting results of hyperthermia in osteosarcoma based on integrative ChIP-Seq/TargetScan analysis. Med Sci Monit. 2017;23:2042-8.

31. Yousef GM. miRSNP-based approach identifies a miRNA that regulates prostate-specific antigen in an allele-specific manner. Cancer Discov. 2015; 5(4):351-2. https://doi.org/10.1158/2159-8290 CD-15-0230.

32. Ning $S$, Zhao Z, Ye J, Wang P, Zhi H, Li R, Wang T, Li X. LincSNP: a database of linking disease-associated SNPs to human large intergenic non-coding RNAs. BMC Bioinform. 2014;15:152. https://doi.org/10.1186/ 1471-2105-15-152.

33. Hsu CH, Chan D, Greggio E, Saha S, Guillily MD, Ferree A, Raghavan K, Shen GC, Segal L, Ryu H, et al. MKK6 binds and regulates expression of Parkinson's disease-related protein LRRK2. J Neurochem. 2010;112(6):1593604. https://doi.org/10.1111/j.1471-4159.2010.06568.x.

34. Vivarelli S, Lenzken SC, Ruepp MD, Ranzini F, Maffioletti A, Alvarez R, Muhlemann O, Barabino SM. Paraquat modulates alternative pre-mRNA splicing by modifying the intracellular distribution of SRPK2. PLoS One. 2013;8(4):e61980. https://doi.org/10.1371/journal.pone.0061980.

35. Alawdi SH, El-Denshary ES, Safar MM, Eidi H, David MO, Abdel-Wahhab MA. Neuroprotective effect of nanodiamond in Alzheimer's disease rat model: a pivotal role for modulating NF-kappaB and STAT3 signaling. Mol Neurobiol. 2017;54(3):1906-18. https://doi.org/10.1007/s12035-016-9762-0.

36. Soldner F, Stelzer Y, Shivalila CS, Abraham BJ, Latourelle JC, Barrasa MI, Goldmann J, Myers RH, Young RA, Jaenisch R. Parkinson-associated risk variant in distal enhancer of alpha-synuclein modulates target gene expression. Nature. 2016;533(7601):95-9. https://doi.org/10.1038/ nature17939.

37. Banerjee D, Nandagopal K. Potential interaction between the GARS-AIRSGART Gene and CP2/LBP-1 C/LSF transcription factor in down syndromerelated Alzheimer disease. Cell Mol Neurobiol. 2007;27(8):1117-26.

38. Potashkin JA, Santiago JA, Ravina BM, Watts A, Leontovich AA. Biosignatures for Parkinson's disease and atypical parkinsonian disorders patients. PLoS One. 2012;7(8):e43595. https://doi.org/10.1371/journal.pone.0043595.

39. Yi F, Pereira L, Hoffman JA, Shy BR, Yuen CM, Liu DR, Merrill BJ. Opposing effects of Tcf3 and Tcf1 control Wht stimulation of embryonic stem cell selfrenewal. Nat Cell Biol. 2011;13(7):762-70. https://doi.org/10.1038/ncb2283.

40. Atlasi Y, Noori R, Gaspar C, Franken P, Sacchetti A, Rafati H, Mahmoudi T, Decraene C, Calin GA, Merrill BJ, et al. Wnt signaling regulates the lineage differentiation potential of mouse embryonic stem cells through Tcf3 down-regulation. PLoS Genet. 2013;9(5):e1003424. https://doi.org/10.1371/ journal.pgen.1003424.

41. Zaghlool A, Halvardson J, Zhao JJ, Etemadikhah M, Kalushkova A, Konska K, Jernberg-Wiklund H, Thuresson AC, Feuk L. A Role for the Chromatinremodeling factor BAZ1A in neurodevelopment. Hum Mutat. 2016;37(9): 964-75. https://doi.org/10.1002/humu.23034.

42. Johnson MB, Kawasawa YI, Mason CE, Krsnik Z, Coppola G, Bogdanovic D, Geschwind DH, Mane SM, State MW, Sestan N. Functional and evolutionary insights into human brain development through global transcriptome analysis. Neuron. 2009;62(4):494-509. https://doi.org/10. 1016/j.neuron.

43. Uhlen M, Fagerberg L, Hallstrom BM, Lindskog C, Oksvold P, Mardinoglu A, Sivertsson A, Kampf C, Sjostedt E, Asplund A, et al. Proteomics. Tissue-based map of the human proteome. Science. 2015;347(6220):1260419. https://doi. org/10.1126/science.1260419.

44. Di Gregorio E, Bianchi FT, Schiavi A, Chiotto AM, Rolando M, Verdun di Cantogno L, Grosso E, Cavalieri S, Calcia A, Lacerenza D, et al. A de novo X;8 translocation creates a PTK2-THOC2 gene fusion with THOC2 expression knockdown in a patient with psychomotor retardation and congenital cerebellar hypoplasia. J Med Genet. 2013;50(8):543-51. https://doi.org/10. 1136/jmedgenet-2013-101542. 
45. Beausoleil SA, Villen J, Gerber SA, Rush J, Gygi SP. A probability-based approach for high-throughput protein phosphorylation analysis and site localization. Nat Biotechnol. 2006;24(10):1285-92.

46. Viphakone N, Cumberbatch MG, Livingstone MJ, Heath PR, Dickman MJ, Catto JW, Wilson SA. Luzp4 defines a new mRNA export pathway in cancer cells. Nucleic Acids Res. 2015;43(4):2353-66. https://doi.org/10.1093/nar/ gkv070

47. Fujinami $\mathrm{K}$, Uemura $H$, Ishiguro $H$, Kubota Y. Liprin-alpha2 gene, protein tyrosine phosphatase LAR interacting protein related gene, is downregulated by androgens in the human prostate cancer cell line LNCaP. Int J Mol Med. 2002;10(2):173-6.

48. Bentin Toaldo C, Alexi X, Beelen K, Kok M, Hauptmann M, Jansen M, Berns E, Neefjes J, Linn S, Michalides R, et al. Protein Kinase A-induced tamoxifen resistance is mediated by anchoring protein AKAP13. BMC Cancer. 2015;15:588. https://doi.org/10.1186/s12885-015-1591-4.

49. Virok DP, Simon D, Bozso Z, Rajko R, Datki Z, Balint E, Szegedi V, Janaky T, Penke B, Fulop L. Protein array based interactome analysis of amyloid-beta indicates an inhibition of protein translation. J Proteome Res. 2011;10(4): 1538-47. https://doi.org/10.1021/pr1009096.

50. Goldspink DA, Rookyard C, Tyrrell BJ, Gadsby J, Perkins J, Lund EK, Galjart N, Thomas P, Wileman T, Mogensen MM. Ninein is essential for apico-basal microtubule formation and CLIP-170 facilitates its redeployment to noncentrosomal microtubule organizing centres. Open Biol. 2017;7(2) https:// doi.org/10.1098/rsob.160274.

51. Schubert KO, Focking M, Prehn JH, Cotter DR. Hypothesis review: are clathrin-mediated endocytosis and clathrin-dependent membrane and protein trafficking core pathophysiological processes in schizophrenia and bipolar disorder? Mol Psychiatry. 2012;17(7):669-81. https://doi.org/10.1038/ mp.2011.123.

52. Bruggemann $M$, Gromes $A$, Poss $M$, Schmidt D, Klumper N, Tolkach $Y$, Dietrich D, Kristiansen G, Muller SC, Ellinger J. Systematic analysis of the expression of the mitochondrial ATP Synthase (Complex V) subunits in clear cell renal cell carcinoma. Transl Oncol. 2017;10(4):661-8. https:// doi.org/10.1016/j.tranon.2017.06.002.

53. Larsen SB, Hanss Z, Kruger R. The genetic architecture of mitochondrial dysfunction in Parkinson's disease. Cell Tissue Res. 2018; https://doi.org/10. 1007/s00441-017-2768-8

54. Alieva A, Filatova EV, Karabanov AV, Illarioshkin SN, Limborska SA, Shadrina MI, Slominsky PA. miRNA expression is highly sensitive to a drug therapy in Parkinson's disease. Parkinsonism Relat Disord. 2015;21(1):72-4. https://doi. org/10.1016/j.parkreldis.2014.10.018.

55. Wang Z, Guo D, Yang B, Wang J, Wang R, Wang X, Zhang Q. Integrated analysis of microarray data of atherosclerotic plaques: modulation of the ubiquitin-proteasome system. PLoS One. 2014;9(10):e110288. https://doi.org/ 10.1371/journal.pone.0110288.

56. Chen H, Mosley TH, Alonso A, Huang X. Plasma urate and Parkinson's disease in the atherosclerosis risk in communities (ARIC) study. Am J Epidemiol. 2009;169(9):1064-9. https://doi.org/10.1093/aje/kwp033.

57. Li Q, Yang Z, Lu B, Wen J, Ye Z, Chen L, He M, Tao X, Zhang W, Huang Y, et al. Serum uric acid level and its association with metabolic syndrome and carotid atherosclerosis in patients with type 2 diabetes. Cardiovasc Diabetol. 2011;10:72. https://doi.org/10.1186/1475-2840-10-72.

58. Chatterjee P, Roy D. Comparative analysis of RNA-Seq data from brain and blood samples of Parkinson's disease. Biochem Biophys Res Commun. 2017; 484(3):557-64. https://doi.org/10.1016/j.bbrc.2017.01.121.

59. Chow AM, Mok P, Xiao D, Khalouei S, Brown IR. Heteromeric complexes of heat shock protein 70 (HSP70) family members, including Hsp70B', in differentiated human neuronal cells. Cell Stress Chaperones. 2010;15(5):545-53. https://doi.org/10.1007/s12192-0090167-0.

60. Khalouei S, Chow AM, Brown IR. Localization of heat shock protein HSPA6 (HSP70B') to sites of transcription in cultured differentiated human neuronal cells following thermal stress. J Neurochem. 2014;131(6):743-54. https://doi. org/10.1111/jnc.12970.

61. Doci CL, Mankame TP, Langerman A, Ostler KR, Kanteti R, Best T, Onel K, Godley LA, Salgia R, Lingen MW. Characterization of NOL7 gene point mutations, promoter methylation, and protein expression in cervical cancer. Int J Gynecol Pathol. 2012;31(1):15-24. https://doi.org/10.1097/PGP. Ob013e318220ba16.

62. Chen ZC, Zhang W, Chua LL, Chai C, Li R, Lin L, Cao Z, Angeles DC, Stanton $\mathrm{LW}$, Peng JH, et al. Phosphorylation of amyloid precursor protein by mutant
LRRK2 promotes AICD activity and neurotoxicity in Parkinson's disease. Sci Signal. 2017;10(488) https://doi.org/10.1126/scisignal.aam6790.

63. Myhre R, Toft M, Kachergus J, Hulihan MM, Aasly JO, Klungland H, Farrer MJ. Multiple alpha-synuclein gene polymorphisms are associated with Parkinson's disease in a Norwegian population. Acta Neurol Scand. 2008; 118(5):320-7. https://doi.org/10.1111/j.1600-0404.2008.01019.x.

64. Kettunen E, Anttila S, Seppanen JK, Karjalainen A, Edgren H, Lindstrom I, Salovaara R, Nissen AM, Salo J, Mattson K, et al. Differentially expressed genes in nonsmall cell lung cancer: expression profiling of cancer-related genes in squamous cell lung cancer. Cancer Genet Cytogenet. 2004;149(2): 98-106. https://doi.org/10.1016/S0165-4608(03)00300-5.

65. Klein F, Feldhahn N, Mooster JL, Sprangers M, Hofmann WK, Wernet $P$, Wartenberg $M$, Muschen $M$. Tracing the pre-B to immature B cell transition in human leukemia cells reveals a coordinated sequence of primary and secondary IGK gene rearrangement, IGK deletion, and IGL gene rearrangement. J Immunol. 2005;174(1):367-75.

66. Watson RP, Tekki-Kessaris N, Boulter CA. Characterisation, chromosomal localisation and expression of the mouse Kid3 gene. Biochim Biophys Acta. 2000;1490(1-2):153-8.

67. Satoh J, Asahina N, Kitano S, Kino Y. A Comprehensive Profile of ChIP-SeqBased PU.1/Spi1 Target Genes in Microglia. Gene Regul Syst Bio. 2014;8:12739. https://doi.org/10.4137/GRSB.S19711.

68. Huang KL, Marcora E, Pimenova AA, Di Narzo AF, Kapoor M, Jin SC, Harari O, Bertelsen S, Fairfax BP, Czajkowski J, et al. A common haplotype lowers PU.1 expression in myeloid cells and delays onset of Alzheimer's disease. Nat Neurosci. 2017;20(8):1052-61. https://doi.org/10.1038/nn.4587.

69. Marques TM, Kuiperij HB, Bruinsma IB, van Rumund A, Aerts MB, Esselink RAJ, Bloem BR, Verbeek MM. MicroRNAs in cerebrospinal fluid as potential biomarkers for Parkinson's disease and multiple system atrophy. Mol Neurobiol. 2017;54(10):7736-45. https://doi.org/10.1007/s12035-016-0253-0.

70. Botta-Orfila T, Morato X, Compta Y, Lozano JJ, Falgas N, Valldeoriola F, PontSunyer C, Vilas D, Mengual L, Fernandez M, et al. Identification of blood serum micro-RNAs associated with idiopathic and LRRK2 Parkinson's disease. J Neurosci Res. 2014;92(8):1071-7. https://doi.org/10.1002/jnr.23377.

71. Delay C, Calon F, Mathews P, Hebert SS. Alzheimer-specific variants in the 3'UTR of Amyloid precursor protein affect microRNA function. Mol Neurodegener. 2011;6:70. https://doi.org/10.1186/1750-1326-6-70.

72. Chang SJ, Weng SL, Hsieh JY, Wang TY, Chang MD, Wang HW. MicroRNA34a modulates genes involved in cellular motility and oxidative phosphorylation in neural precursors derived from human umbilical cord mesenchymal stem cells. BMC Med Genet. 2011;4:65. https://doi.org/10. 1186/1755-8794-4-65.

73. Zhou B, Zhao H, Yu J, Guo C, Dou X, Song F, Hu G, Cao Z, Qu Y, Yang Y, et al. EVLnCRNAs: a manually curated database for long non-coding RNAs validated by low-throughput experiments. Nucleic Acids Res. 2018;46(D1): D100-D5. https://doi.org/10.1093/nar/gkx677.

74. Nishimoto Y, Nakagawa S, Hirose T, Okano HJ, Takao M, Shibata S, Suyama S, Kuwako K, Imai T, Murayama S, et al. The long non-coding RNA nuclearenriched abundant transcript 1_2 induces paraspeckle formation in the motor neuron during the early phase of amyotrophic lateral sclerosis. Mol Brain. 2013;6:31. https://doi.org/10.1186/1756-6606-6-31.

75. Singh M. Dysregulated A to I RNA editing and non-coding RNAs in neurodegeneration. Front Genet. 2012;3:326. https://doi.org/10.3389/fgene. 2012.00326

76. Johnson R. Long non-coding RNAs in Huntington's disease neurodegeneration. Neurobiol Dis. 2012;46(2):245-54. https://doi.org/10. 1016/j.nbd.2011.12.006.

77. Toffoli M, Dreussi E, Cecchin E, Valente M, Sanvilli N, Montico M, Gagno S, Garziera M, Polano M, Savarese M, et al. SNCA 3'UTR genetic variants in patients with Parkinson's disease and REM sleep behavior disorder. Neurol Sci. 2017;38(7):1233-40. https://doi.org/10.1007/s10072-017-2945-2.

78. Sotiriou S, Gibney G, Baxevanis AD, Nussbaum RL. A single nucleotide polymorphism in the $3^{\prime} U$ TR of the SNCA gene encoding alpha-synuclein is a new potential susceptibility locus for Parkinson disease. Neurosci Lett. 2009;461(2):196-201. https://doi.org/10.1016/j.neulet.2009.06.034.

79. Ben Fredj N, Rizzo R, Bortolotti D, Nefzi F, Chebel S, Rotola A, Frih-Ayed M, Di Luca D, Aouni M. Evaluation of the implication of KIR2DL2 receptor in multiple sclerosis and herpesvirus susceptibility. J Neuroimmunol. 2014; 271(1-2):30-5. https://doi.org/10.1016/j.jneuroim.2014.03.017.

80. Ban JJ, Chung JY, Lee M, Im W, Kim M. MicroRNA-27a reduces mutant hutingtin aggregation in an in vitro model of Huntington's disease. 
Biochem Biophys Res Commun. 2017;488(2):316-21. https://doi.org/10.1016/ j.bbrc.2017.05.040.

81. Sala Frigerio C, Lau P, Salta E, Tournoy J, Bossers K, Vandenberghe R, Wallin A, Bjerke M, Zetterberg $H$, Blennow K, et al. Reduced expression of hsa-miR27a-3p in CSF of patients with Alzheimer disease. Neurology. 2013;81(24): 2103-6. https://doi.org/10.1212/01.wnl.0000437306.37850.22.

82. Yan H, Li Q, Wu J, Hu W, Jiang J, Shi L, Yang X, Zhu D, Ji M, Wu C. MiR-629 promotes human pancreatic cancer progression by targeting FOXO3. Cell Death Dis. 2017;8(10):e3154. https://doi.org/10.1038/cddis.2017.525.

83. Jiang J, Zhang Y, Guo Y, Yu C, Chen M, Li Z, Tian S, Sun C. MicroRNA-3127 promotes cell proliferation and tumorigenicity in hepatocellular carcinoma by disrupting of PI3K/AKT negative regulation. Oncotarget. 2015;6(8):635972. https://doi.org/10.18632/oncotarget.3438.

84. Sibley CR, Seow Y, Curtis H, Weinberg MS, Wood MJ. Silencing of Parkinson's disease-associated genes with artificial mirtron mimics of miR1224. Nucleic Acids Res. 2012;40(19):9863-75. https://doi.org/10.1093/nar/ gks712.

85. Wei P, Li L, Zhang Z, Zhang W, Liu M, Sheng X. A genetic variant of miR-335 binding site in the ERBB4 $3^{\prime}-U T R$ is associated with prognosis of ovary cancer. J Cell Biochem. 2017; https://doi.org/10.1002/jcb.26488.

86. Pehserl AM, Ress AL, Stanzer S, Resel M, Karbiener M, Stadelmeyer E, Stiegelbauer V, Gerger A, Mayr C, Scheideler M, et al. Comprehensive analysis of miRNome alterations in response to sorafenib treatment in colorectal cancer cells. Int J Mol Sci. 2016;17(12):2011. https://doi.org/10. 3390/ijms17122011.

87. Zheng G, Wang H, Zhang X, Yang Y, Wang L, Du L, Li W, Li J, Qu A, Liu Y, et al. Identification and validation of reference genes for QPCR detection of serum microRNAs in colorectal adenocarcinoma patients. PLoS One. 2013; 8(12):e83025. https://doi.org/10.1371/journal.pone.0083025.

88. Xu CZ, Xie J, Jin B, Chen XW, Sun ZF, Wang BX, Dong P. Gene and microRNA expression reveals sensitivity to paclitaxel in laryngeal cancer cell line. Int J Clin Exp Pathol. 2013;6(7):1351-61.

89. De-Ugarte L, Caro-Molina E, Rodriguez-Sanz M, Garcia-Perez MA, Olmos JM, Sosa-Henriquez M, Perez-Cano R, Gomez-Alonso C, Del Rio L, Mateo-Agudo J, et al. SNPs in bone-related miRNAs are associated with the osteoporotic phenotype. Sci Rep. 2017;7(1):516. https://doi.org/10.1038/s41598-01700641-7.

90. Shamir R, Klein C, Amar D, Vollstedt EJ, Bonin M, Usenovic M, Wong YC, Maver A, Poths S, Safer $\mathrm{H}$, et al. Analysis of blood-based gene expression in idiopathic Parkinson disease. Neurology. 2017;89(16):1676-83. https://doi. org/10.1212/WNL.0000000000004516.

91. Scherzer CR, Eklund AC, Morse LJ, Liao Z, Locascio JJ, Fefer D, Schwarzschild MA, Schlossmacher MG, Hauser MA, Vance JM, et al. Molecular markers of early Parkinson's disease based on gene expression in blood. Proc Natl Acad Sci U S A. 2007;104(3):955-60. https://doi.org/10.1073/pnas.0610204104.

92. Calligaris R, Banica M, Roncaglia P, Robotti E, Finaurini S, Vlachouli C Antonutti L, lorio F, Carissimo A, Cattaruzza T, et al. Blood transcriptomics of drug-naive sporadic Parkinson's disease patients. BMC Genomics. 2015;16: 876. https://doi.org/10.1186/s12864-015-2058-3.

93. Lesnick TG, Papapetropoulos S, Mash DC, Ffrench-Mullen J, Shehadeh L, de Andrade M, Henley JR, Rocca WA, Ahlskog JE, Maraganore DM. A genomic pathway approach to a complex disease: axon guidance and Parkinson disease. PLoS Genet. 2007;3(6):e98. https://doi.org/10.1371/journal.pgen. 0030098.

94. Moran LB, Duke DC, Deprez M, Dexter DT, Pearce RK, Graeber MB. Whole genome expression profiling of the medial and lateral substantia nigra in Parkinson's disease. Neurogenetics. 2006;7(1):1-11. https://doi.org/10.1007/ s10048-005-0020-2.

95. Zheng B, Liao Z, Locascio JJ, Lesniak KA, Roderick SS, Watt ML, Eklund AC, Zhang-James Y, Kim PD, Hauser MA, et al. PGC-1alpha, a potential therapeutic target for early intervention in Parkinson's disease. Sci Transl Med. 2010;2(52):52ra73. https://doi.org/10.1126/scitransImed.3001059.

\section{Submit your next manuscript to BioMed Central and we will help you at every step:}

- We accept pre-submission inquiries

- Our selector tool helps you to find the most relevant journal

- We provide round the clock customer support

- Convenient online submission

- Thorough peer review

- Inclusion in PubMed and all major indexing services

- Maximum visibility for your research

Submit your manuscript at www.biomedcentral.com/submit
( ) BioMed Central 